How does Initial Teacher Education Research Frame the Challenge of Preparing Future Teachers for Student Diversity in Schools: A Systematic Review of Literature 


\begin{abstract}
Teachers consistently identify working with "diverse learners" as challenging. This raises questions about how teacher educators conceptualize and enact preparation of teachers for heterogeneous populations. This paper provides a systematic review of literature relating to both "teacher education" and "diverse learners", to identify knowledge claims regarding the way this "problem" and possible "solutions" should be framed. Analyzing 209 peer-reviewed journal articles (2009-2019), the paper identifies: groups most frequently described as diverse; three qualitatively different clusters of claims regarding how teachers can be prepared for diversity; and factors identified as constraining preparation. Analysis reveals a literature broad in focusreferencing many groups - but shallow in depth. The majority describe strategies for teaching about or catering to diversity with only few considering teaching for diversity. There is also limited engagement with specialist literature relating to concepts such as gender or race and little attention to teacher educators' own knowledge. The paper concludes with implications for teacher educators, arguing for enhanced critical epistemic reflexivity.
\end{abstract}

Keywords: initial teacher education, teacher educators, diversity in schools, diverse learners, schools, social justice 


\section{How does Initial Teacher Education Research Frame the Challenge of Preparing Future Teachers for Student Diversity in Schools: A Systematic Review of Literature}

This paper reports a systematic review of the specific body of literature that addresses two interrelated topics: teacher education and the preparation of teachers to work appropriately and confidently with "diverse" learners. The review has emerged from the authors' sustained consideration of three problems impacting on our work as teacher educators: problems that are also highlighted within the large volume of research, policy, and public commentary that centers on teacher education. The first concerns data which consistently show that some groups of students are more likely than others to benefit from their schooling and educational experiences. In 1999, Marilyn Cochran-Smith and eight of her colleagues introduced a paper focused on the work of teacher education with reference to "mounting evidence that the present educational system is failing to serve disproportionately large numbers of children who are not part of the mainstream" (Cochran-Smith et al., 1999, p. 229). Over 20 years later, evidence continues to demonstrate that some groups of learners are more consistently advantaged by educational systems than others (Mills, et al., 2019). Some members of each population-including people who may or may not be statistical "minorities" - are more likely than others to experience schooling as a place where they are minoritized and/or marginalized. Factors such as cultural background, first language, place of birth, geographical location, socioeconomic status, gender, sexual identity and family form have all been shown to influence educational experiences, pathways, and outcomes, and each of these terms is now commonly spoken about as a form of demographic and cultural "diversity" that has been made to matter in social and educational contexts (for overviews of these discussions, see Groundwater-Smith et al., 2011; Keddie, 2012; Rowan, 2018). The authors of this paper share a belief that education should ultimately function as an instrument of social transformation (not social reproduction) and thus the persistent pattern of educational success and failure is the first concern informing this paper. 
The second related issue concerns the lack of confidence teachers feel regarding their ability to work effectively with learners who are understood in some way as diverse. Over recent years, governments and policymakers across the world have invested in multiple mechanisms to try to "improve" the quality of the teaching profession generally and to close various gaps in attendance and achievement. This agenda has seen a growing use of the term "diverse learners" within policies such as professional standards frameworks. Some of these policies use the term diversity as a synonym for population variation; others link it to very particular population subcategories. For example, in the UK, Teachers' Standard 5 states that teachers must “adapt teaching to respond to the strengths and needs of all pupils" (Department for Education, 2011/2013) and makes particular mention of pupils with special educational needs, those of high ability, those with English as an additional language, and those with disabilities. Australia's Professional Standards for Teachers include references to diversity, mainly within Standard $1-$ Know students and how they learn, and makes reference to students from diverse linguistic, cultural, religious and socioeconomic backgrounds (AITSL, 2017). But, despite growing attention to the broad theme of diversity within teacher education policy and programs, research across many countries (e.g. the United States, Canada, Korea, Sweden, The Netherlands, Australia, and France) has persistently shown that for many teachers, including new graduates, working with the groups referred to either specifically or generically as diverse learners is still experienced as challenging and complex (Chang, 2008; Colon-Muniz et al., 2010; Rowan et al., 2017).

These persistent, truly wicked patterns of educational success and failure and the equally persistent concerns expressed by teachers frame a third serious problem for teacher educators: what it is that we - as a research-based community — can or should be doing better? Our reference here to the research base associated with teacher education and diverse students is, of course, deliberate. It is this body of knowledge that could reasonably be expected to help us address the challenges outlined above. The literature is voluminous: a fact clearly documented 
by authors such as Cochran-Smith and Villegas (2015a) who identified "Teacher Preparation for Diversity and Equity" as one of the three major (distinct) "programs of research" (p.13) that characterized teacher education research published between 2000-2012. But this body of scholarship is far from unified. It varies in focus and it varies in its underlying ideological assumptions. To give one brief example, in a systematic review of literature published in 2016 (explored further below), Mills and Ballantyne identified 279 articles that included in their abstracts "socially just" or "social justice" and "teacher education" or "teacher educator" and subsequently analyzed only 23 of these 279 papers - those with a focus on preservice education conducted in the last ten years. Significantly, their review deliberately excluded papers that engaged with the concept of 'diversity' but did not use the word social justice in their title thus leaving unexamined papers that may have explored diversity and teacher education using different theoretical lenses. The point we are making here is that the literature which relates to "teacher education" and "diverse learners"- the literature which teacher educators could reasonably be expected to draw upon when responding to the challenges above — is diverse, and not yet understood as fully as it can be.

A lack of clarity about the different and potentially competing messages embedded within literature relating to teacher education and diverse learners has the potential to impact upon the effectiveness of our decisions. Indeed, we share with authors such as Loughran (2014) and Goodwin et al. (2014) the firm belief that learning more about the knowledge base of teacher educators is an important agenda for the teacher education community. Informed by the contextual challenges outlined above - and motivated by the belief that knowing more about the knowledge claims that underpin teacher education scholarship can only improve our ability to meet the needs of diverse students (and their teachers) - this paper provides a systematic review of literature that relates to both "teacher education" and "diverse learners". With an interest in identifying ways we can do better, we focus not on demonstrating the volume of the literature (that work has already been done: see, for example, Cochran-Smith \& Villegas, 2015b), nor on 
illustrating the recommendations about teacher education that are contained within particular sub-strands of this literature, (such as Sleeter \& Owour's (2011) analyzes of initial teacher education approaches to multi-cultural education or Han \& Laughter's (2019) overview of how critical race theory can shape teachers). Rather, our goal is to approach the literature from a new direction: seeking not to re-state the questions addressed in this large body of scholarship, but rather to identify the different knowledge claims about "preparation for diversity" upon which the literature is based.

Directed specifically at those who work in, and research about, teacher education, the review is presented in five main sections. In the first, we acknowledge the complex and contested nature of the terms, diversity and diverse learners. We explain why these terms have been selected to frame this review and the way our existing familiarity with the associated literature frames the analysis. In the second we provide an overview of previous systematic reviews that have looked at similar combinations of terms and emphasize the unique focus of this review: that is, analysis of the knowledge claims about diversity and teacher preparation that underpin the papers we analyze. From this basis we outline, in section three, the methods and research questions we employed to identify and select the included papers. In the fourth section we present the results of the review, identifying original insights of relevance to teacher educators and others with a stake in educational outcomes. We conclude, in the fifth section, with a discussion that identifies implications for teacher educators and puts forward what we believe to be new questions that can take teacher education research forward into the future: questions that may improve our ability to meet the needs of initial teacher education (ITE) students and, by extension, the needs of diverse students in diverse learning environments.

Before moving into an overview of the design and conduct of the review it is necessary for us to acknowledge that the term at the heart of this paper-diverse learners-is not without complications and that we bring to the review existing knowledge about some of the different, 
commonly recognized ways in which educators write about what it means to respond effectively to student diversity. We review some of the related issues briefly now.

\section{Theoretical Reflections on Diversity and Teacher Education}

Our decision to organize the review around the term diversity is both cautious and deliberate. As already noted, the term has a growing presence in educational policy and public rhetoric where it often functions as a kind of "catch all" or shorthand way to reference any/all groups who are in some way regarded as different from the kinds of learners who (according to research) are most/more likely to experience educational success. Teachers consistently report working with diverse learners as one of the most challenging aspects of their work and teacher educators should therefore be able to answer questions about the ways we respond to this context. Developing a clearer understanding of how teacher education literature constructs the challenge of "student diversity" — and, by extension, how it represents the knowledge of a "prepared" teacher-is an important step in this process.

However, it is also important for us to remain aware that the term diversity (and thus preparation for diversity) can be deployed in various ways. Perspectives on diversity exist on a complex continuum: a continuum that ranges from essentialist and assimilationist views through to anti-essentialist and transformative perspectives. Literature has shown that representing some students as diverse, constructs others (by default) as "mainstream" or "normal", serving to generate the kinds of binary relationships between "us" and "them" that are widely recognized as central to the very beliefs and structures that lead to the experiences of social and educational inequity in the first place (the creation of an "us" and a "them" is predicated on these binaries). Authors such as Banks et al. (2005), Francis et al. (2017) and Mills et al. (2019) have all demonstrated that at the same time as educators work to see and acknowledge the way meanings have been attached to differences in various historical and cultural contexts - the way differences are made to matter - we must be conscious of the ways in which we ourselves can portray these 
meanings as natural, rather than artificial or as "facts" to be accommodated or tolerated, or constructions that can be undone.

These issues have shaped our review in important ways. First, we recognize that if we want to develop an understanding of the "state of the field" in regard to ITE and "diversity" —as the term is used in policy and everyday educational discourse - then using the word diversity is a necessary move. To put it simply: we have to use the term diversity because it is a term in use. Second, we also know that (for the reasons discussed above) some authors prefer to use more specific terms to acknowledge and speak about student differences: terms such as gender, sexual identity, location, family form, religion, ethnicity, race or cultural identity, Indigenous identity, or socioeconomic status. We therefore included all of these terms in our literature review search strategy.

Third, if this review is to be helpful to teacher educators who are genuinely struggling to address long-standing patterns of educational success and failure, we need to try and look at this persistent problem from a new angle. As noted above, previous explorations of the relevant literature (systematic reviews or otherwise) have generally focused on either identifing the thematic foci of a broad range of papers (eg Cochran-Smith \& Villegas, 2015a) or summarising the recommendations (for practice) contained within strands of the literature. This paper takes a different approach, seeking to identify not the recommendations of each paper, but rather the foundational assumptions - the knowledge claims - about what preparation for diversity actually involves. This approach, we argue, offers a new pespective from which we can reflect upon the historical failure of teacher education to graduate teachers who feel confident in their ability to work with hetereogenous student populations.

Taken together, these three insights have informed the design of a systematic review that seeks to consider both the breadth of research and the depth of the research related to diverse learners and teacher preparation. This focus, we argue, will provide teacher eductors with a mapping of the literature that is sufficiently nuanced and sufficiently detailed to be theoretically 
and practically useful for those wishing to address our key concern: improving the ability of teacher education to prepare teachers for a hetereogenous population.

\section{An Overview of Previous Systematic Reviews on Diversity and Initial Teacher Education}

Systematic reviews are commonly described as clear, unambiguous, and precise ways to review literature and enable replication of the search process (Moher et al., 2015) and can be beneficial for identifying gaps and pointing to future research directions (Ives, 2020; Petticrew \& Roberts, 2008). By using a predefined methodological approach and applying explicit inclusion and exclusion criteria, they offer a comprehensive identification, classification, and synthesis of the core area of research under investigation (Hofmann et al., 2011). As a result, systematic reviews are common in a range of professions including psychology and public health and are becoming more widespread in education (Alexander, 2020).

While the broad literature relating to teacher preparation is large (a point we acknowledge in our introduction) and includes many important summaries or overviews of scholarly research relating to preparation of teachers for diverse contexts, there have been, to date, very few systematic reviews that have focused explicitly on questions relating to how teacher education can best prepare future teachers to work with learners identified as diverse. Some systematic reviews might be usefully thought of as running parallel to the work proposed in this current review, for they are interested in diversity and diverse learners, but focus on schools (not teacher education) and/or consider only one particular group of learners. For example, Avramidis and Norwich (2002), de Boer et al. (2011), Lautenbach and Heyder (2019), Qi and Ha (2012), and Wilhelmsen and Sørensen (2017) focused their systematic reviews on teachers' views about inclusion and, thus, the experiences of students with disabilities. In a further example, Francis (2017) undertook a review of literature on the schooling experiences of lesbian, gay, bisexual, and transgender youths and how schools respond (or not) to issues of gender and sexuality diversity in South Africa. Although these studies have provided sound 
pieces of scholarship linked to diverse learners, some are geographically situated, some consider only particular aspects of diversity, and none focus on ITE specifically.

There are, however, some reviews of this ilk where the focus is ITE. We review these briefly here to further demonstrate the contribution to knowledge made by the current paper. First, Hollins and Guzman's (2005) review examined empirical US-based studies published between 1980 and 2002. These writers focused on the preparation of teachers for underserved populations including students of color, low socio-economic backgrounds, language minorities and those living in urban and rural settings. Specifically, they reported on pre-service teachers' dispositions, preparation of those prospective teachers, the experiences of candidates of color and studies related to program evaluations. This review found that although research in this field had increased compared with earlier reviews such as, for example, the study reported by Grant and Secada (1990), larger scale longitudinal studies underpinned by robust theoretical frames were still generally absent. However, Hollins and Guzman's review was conducted more than fifteen years ago. As well as this, it was limited to the USA and did not seek to identify knowledge claims about diversity that underpinned each paper. Additionally, the review did not report detailed search terms and inclusion/exclusion criteria to enable replication.

More recently, the examination of peer reviewed journal articles published between 2000 and 2014 by Kline et al. (2014) concentrated on how education researchers working in diverse rural spaces utilized ethical frameworks in their practice. The thirty reviewed studies led the writers to conclude that the literature at the intersection of rural ethics, inclusive education and teacher educators' positionality is scarce, providing "erratic" directions for future research in culturally diverse communities. Although this review can be regarded as systematic, the field of investigation is focused on only one diversity referent, and, as such, is much narrower than what we examine in this current study.

One of the more recent, broader systematic reviews in the ITE/diversity space is by Mills and Ballantyne (2016). As noted in our introduction, these writers undertook a systematic 
review of empirical peer-reviewed research between 2006 and 2016 which focused on social justice and teacher education. Their interests lay in how teacher education programs prepare preservice teachers to engage with student diversity with respect to racial/ethnic, gendered, cultural, linguistic, religious, and socioeconomic backgrounds, learning difficulties, disabilities, and sexual orientation in what they refer to as "socially just" ways. Like ourselves, these authors considered multiple forms of diversity but included in their review only those papers (within a specified time frame) that referenced social justice in their titles (Mills \& Ballantyne, 2016). Thus, although this review has the potential to improve how "social justice" is understood within the included papers, it cannot provide insights into the papers that were excluded. Thus, by extension, the review is only able to provide a partial mapping of the knowledge claims within the associated literature. As well as this, the 23 articles that were analyzed mostly focused on preservice teachers, except one that also included teacher educators in the data set.

To summarize, then, the previous systematic reviews that are located at the intersection of conversations about the work of teacher education and preparation of teachers for diverse learners have undertaken important work, but focused primarily on:

- only one, or a sub-set of diversity references,

- the experiences/actions of teachers in schools or preservice teachers rather than teacher educators' practices; and/or,

- research that is explicitly badged as aligned with social justice scholarship, thus excluding papers that draw on different theoretical traditions; and/or,

- the challenge of drawing conclusions from research projects that are often small scale (and underfunded) and commonly regarded as inconsistent and inconclusive.

Although the resultant papers have contributed valuable knowledge to teacher education, they have left under-examined questions about the way teacher education research in the 
broadest sense speaks to questions associated with knowledge claims about teacher preparation and diverse school students or the trends within this literature.

Having provided this overview of previous systematic reviews that connect to the topic of the current paper, we believe it is also important to acknowledge here that other authors, using different methodological and analytical approaches have also provided mappings or interpretations that connect to the body of literature we are concerned with in this paper. These different mappings add value to the teacher educators' knowledge base, but serve a different purpose to the current review as they have generally focused on providing either a 'big picture' mapping of a large body of literature, or a more fine-grained reading of a specific and relatively narrow sub-set of that literature.

For example, Cochran-Smith and Villegas have provided a valuable "overview of the field" that is "teacher preparation research" to identify the key features of that body of scholarship. The authors conducted a comprehensive hand search of the national and international literature and targeted (but not systematic) electronic searches of relevant teacher education topics to yield 1500 studies for analysis. As a result, they identified three distinct "programs" of teacher education research made up of 14 research "clusters" relating to specific themes and topics (2015a). Research Program C was titled "Teacher Preparation for Diversity and Equity" and was associated with four thematic 'clusters': (1) the influence of courses and field-based opportunities on learning to teach diverse student populations; (2) strategies for recruiting and preparing a diverse teaching force; (3) analyzes of the content, structures, and pedagogies for preparing teacher candidates for diversity; and, (4) analyzes of teacher educator learning for/experiences with diversity. Through this mapping the authors illustrated the growing interest in the phenomenon of student diversity (and teacher education's responses to this diversity); drew attention to some of the major questions that the associated research has attempted to answer and acknowledged that there is the need for ongoing research in relation to all of the research programs: including the program focused on diversity and equity (Cochran- 
Smith \& Villegas, 2015a; Cochran-Smith, et al., 2015). The linked publications, however, are different from the systematic review we report on in this paper not only because they do not provide the kind of detail about included/excluded papers that is required for a systematic review, but because they do not attempt to provide a systematic analysis of the knowledge claims about diversity that underpin the papers that might fit within Research Program C.

Other papers focus more closely on what various strands of literature have to say about a selection of diversity referents — and implications for teacher education—-but, once again, do not use the methodology of systematic review to frame their analysis and do not attempt to identify the beliefs about diversity that underpin the papers they review. To give three examples: Castro's (2010) study reported a change-over-time analysis of millennial preservice teachers' views about cultural diversity, multicultural education, and social justice of studies based upon a review of studies published between 1985 and 2007. The paper explored the ways preservice teachers accepted and appreciated multicultural education and teaching in culturally diverse contexts and provides valuable and important recommendations to teacher educators, emphasising the need to provide opportunities for pre-service teachers to interrogate their prior experiences, cultural assumptions, and racial ideologies. The paper, however, was not a systematic review, nor (in the author's words) an "exhaustive review of the literature" (p.199) and was focused on only a sub-set of the diversity referents considered in this paper.

A second example is provided by Sleeter's (2008) report on findings drawn from empirical studies published after 1980, that explored the effects that teacher education had on the attitudes, knowledge or behaviors of White teachers relative to teaching students of color or language minority. Again, this influential study was not a systematic review of the literature per $s e$, and was confined to consideration of cultural and/or linguistic diversity. Similarly, Sleeter and Owuor (2011) completed a further analysis (again, not a systematic review) of literature relating to teacher education and diversity (particularly as it relates to multicultural education) and noted that there was the need for further, large scale, longitudinal studies "that follow[s] 
teachers through their teacher preparation programs and into their first years of teaching so we can determine the extent and ways multicultural teacher preparation helps them to become better teachers" (p. 534).

Similar to the systematic reviews described above, therefore, different attempts to summarize or map literature related to teacher education and diversity have also been commonly characterized by efforts to:

- demonstrate the breadth and scope of the literature relating to teacher education and diverse learners; and/or,

- summarize literature relating to one diversity referent; and/or,

- illustrate various thematic concerns within the literature through reference to a small subset of papers; and/or,

- $\quad$ argue for further, longitudinal studies relating to one or more diversity referent.

The point we are making with this overview of previous systematic reviews and more descriptive literature summaries is that although the literature associated with teacher education has been investigated and mapped in various ways - including detailed analysis of specific strategies that do or do not appear to impact upon pre-service teachers' sense of capability and capacity — most previous attempts have not kept together the variables that are central to our search strategy: multiple referents of diversity, teacher education, and, the knowledge assumptions that underpin teacher preparation to work with heterogeneous populations. We are thus left with what Alexander (2020) describes as an unanswered but answerable question: what knowledge claims about preparation and diversity underpin the literature that addresses ITE and categories of diversity? Responding to this gap, this review addresses three questions relating to the literature that connects both student diversity and teacher education:

1. What groups of students are (most commonly) referenced as diverse or "at risk" and what are the broad implications of "risk" for teacher education? 
2. What kinds of claims are (most commonly) made about the ways that teacher education can best prepare future teachers to work with diverse learners, specifically with regard to claims relating to content, pedagogies, course/program structure, or other features of ITE that are best suited for preparing teachers for diverse learners?

3. What are the major factors identified as constraining for teacher educators seeking to prepare future teachers to work with diverse learners?

As these questions indicate, our intention is to conduct a review that is interpretive rather than aggregative (Dixon-Woods, 2016) — designed to provide a thematic analysis of trends and patterns rather than a numerical tally - that will have maximum explanatory value in regard to the phenomenon we are investigating: teacher education and preparation for teaching diverse learners.

Consistent with this interpretive objective, the analysis that follows is guided (in both focus and in depth) by the complexity of these three questions. In practical terms this means that Research Question 2 occupies more space in the analysis than Research Questions 1 and 3. This reflects the wider range of themes that are connected to question 2 (outlined in our coding table: Table 1) and our commitment to illustrating all of our claims with reference to a minimum of 10 included articles. This commitment is necessary to ensure that our descriptions have maximum usefulness for our intended audience and that we achieve our goal of illustrating, rather than asserting, the existence of different knowledge claims about what "preparation for diversity" actually means. 


\section{Method}

\section{Literature Search Strategy, Data Bases, and Search Terms}

The PRISMA (Preferred Reporting Items for Systematic Reviews and Meta-Analyzes) protocol as outlined by Moher et al. (2015) provided a foundation for the work of this systematic review. As is standard for systematic reviews, our search strategy (documented below) allows others to replicate our findings.

Five electronic academic literature databases were used in this review: Education Resources Information Center (ERIC), PsychInfo, Education Source, Scopus, and A+ Education. All databases were searched individually for publications using our key terms. Our first key term was "diversity" and common variations "diverse learners", "student diversity", and "diversity in education". Our second group of key terms related to groups of learners commonly badged as diverse or recognized as at risk of educational alienation or failure due to the meanings attached to differences. We began with the terms used by Mills and Ballantyne (2016) in their systematic review: terms relating to "racial/ethnic, gendered, cultural, linguistic, religious, and socio-economic experiences or backgrounds, as well as learning difficulties or disabilities and sexual orientation" (p. 264). We added to the search terms keywords associated with rurality and family form as both are increasingly linked to experiences of educational failure. Synonyms associated with these referents of diversity were identified through searching database-specific thesauruses. Finally, in order to ensure we were capturing papers that had a substantial concern with teacher preparation specifically (not education broadly or work-inschools or the life-worlds of teachers), we added to the search terms synonyms for teacher preparation/initial teacher education and schools.

Table 1 provides a list of the search terms used. Within each search category, terms were joined with the Boolean phrase OR. Between each category, terms were joined with AND. At the completion of all five separate database searches, 533 records were retrieved, and 
bibliographic details of all articles were exported to an EndNote library. Duplicates were identified and removed, resulting in 418 articles for consideration. Article author, date, title, and abstract were then imported into an Excel spreadsheet. Article abstracts were screened for eligibility and coded according to the inclusion/exclusion criteria outlined below.

\section{Inclusion and Exclusion Criteria}

In order to answer the research questions outlined above, and to ensure that our research was of sufficient scale to be fit for stated purpose, we decided to collect and analyze all of the peer-reviewed journal articles published in English between 2009 and 2019 that focused on both the education of diverse learners and implications for teacher education. As well as the obvious point, that this date range allows us to go beyond the years considered in the analyzes cited above, this date range was selected for two reasons. First, it allows us to cover 10 years of literature and thus to ensure that the analysis we conduct is of sufficient size/scale to be regarded as significant to our intended audience. This is important for all systematic reviews but perhaps particularly important for a review concerned with teacher education which (as an area of inquiry) is commonly critiqued for the small size of the data sets that are subjected to analysis. The second reason relates to the local context of the authors. 2019 marked 11 years since the launch of the Melbourne Declaration on Educational Goals for Young Australians (Ministerial Council on Education, Employment, Training and Youth Affairs [MCEETYA], 2008: recently renewed/replaced by the 2020 Alice Springs (Mparntwe) Declaration on Educational Goals for Young Australians) - a document that outlined a commitment to the pursuit of both excellence and equity and the provision of educational opportunities that meet the "diverse needs and aspirations of all young Australians" (MCEETYA, 2008, p. 12). This means that ITE in Australia has been explicitly informed for over a decade now by documents that deploy terms such as diversity. This offers a timely moment to reflect on scholarship related to the field.

Within the 2009-2019 date range, literature was excluded if it was: 
1. An unpublished document or not peer reviewed, including conference proceedings, reports, theses, and book chapters. We recognize that all theses, and some conference papers and book chapters undergo a process of review, but our inability to determine whether or not a book chapter or conference paper was reviewed informed the pragmatic decision to focus on the "non-grey" literature (Alexander, 2020).

2. Not specifically and substantially focused on at least one of the key terms linked to diversity referenced above and outlined below: for example, to be eligible for inclusion, discussion of, or allusions to diversity needed to go beyond the simple provision of background information relating to a particular population, or a concluding paragraph with otherwise unelaborated references to "implications" for diverse learners.

3. Not substantially about ITE: this excluded papers that spoke broadly about education, schools, or schooling systems, but not teacher preparation. We do, of course, recognize that determining whether a paper is explicitly speaking to a teacher education audience or is more overtly interested in the broader phenomenon of education involves the investigators' judgement: this exemplifies the need for systematic reviews to involve both "art" and "science" (Alexander, 2020).

4. Not published in English.

5. A meta-analysis or systematic review. These papers were, however, used to search for any papers that met the above criteria for inclusion that were not picked up in the original search. Many articles cited by these reviews were published before 2009 and were not substantially about ITE and no additional papers were added.

If they were not excluded for any of the above reasons, papers remained in our review regardless of whether or not they reported on empirical data provided they included content relevant to our research questions. In other words, if a paper was focused on one or more diversity referent and advanced arguments about how future teachers can be best prepared to 
work with this diversity and/or identified factors that constrain the work of teacher educators in this regard, it remained in the review.

Using these criteria, all three lead authors for this paper read the abstracts of 418 initially identified articles. Through this process 209 were excluded. Of these excluded papers:

- 102 did not demonstrate a direct or substantial focus on ITE. For example, papers by Borgerding et al. (2015), Pantic (2015), and Payne and Smith (2012) identified implications for teacher educators but only as an afterward in the paper.

- 58 did not have a direct or substantial focus on the identified diversity referents indicated in the search parameters. In this case we eliminated papers that might have used words such as gender or diversity in a title or abstract, but which were not actually using gender (for example) as a category of analysis. Examples of papers excluded include Cheng et al. (2014), Pease-Alvarez and Thompson (2014), and Zschocke et al. (2016).

- 42 were not peer reviewed, including, for example, conference proceedings (Burgess \& Berwick, 2009; Pegg \& Reading, 2009), editorials (Fields \& Payne, 2016; Orlando \& Harreveld, 2014), theses (Maged, 2011; Opie, 2018) or book chapters (Metcalf-Turner, 2009; Rosiek et al., 2017; Ryan et al., 2011).

- 6 were systematic reviews or meta-analyzes (e.g., Castro, 2010; Kline et al., 2014; Mills \& Ballantyne, 2016; Wonseok \& Chepyator-Thomson, 2011).

- One was a duplicate indexed incorrectly.

A summary of the processes and examples of inclusion/exclusion are offered in Figure 1. The full details of the coding process - indicating all included and excluded papers - is available in the supplementary materials for this paper: Table S1 (online only). 


\section{Thematic Coding Process: Phase 1}

The review involved a two-phase, iterative coding process. In Phase 1, our focus was on collecting descriptive information about each paper as expected within a systematic review. In this process we also addressed Research Question 1. Specifically, the first three authors read all 209 abstracts and coded the articles to identify:

1. the diversity referents foregrounded by the authors (e.g., gender, ethnicity, socioeconomic, or the generic term diversity, capturing as many terms as were relevant) and the general reasons why the authors believe we need further research into the associated groups;

2. the location of the study;

3. the data sources for empirical studies (qualitative, quantitative, mixed methods); and,

4. the findings reported by empirical studies and the major arguments advanced within nonempirical papers.

Numerical summaries were generated according to the first three of these categories (shown in Table 2 and Figures $2 \& 3$ ). Study findings/arguments are included in the large coding file included as supplementary Table S1 (online only).

Not surprisingly, we found that papers included in this review were varied in their location, design, and focus. The research reviewed was primarily from North America, where 132 articles were located. This was followed by Europe with 26 and Australasia with 25 (see Figure 2). Just over half of the papers reviewed employed qualitative methods for conducting the research, and $15 \%$ had a quantitative design. Some papers $(15 \%)$ used both qualitative and quantitative; nearly a fifth were non-empirical (see Figure 3). This process also gave us an opportunity to reflect on paper quality. 


\section{A Note on Paper Quality}

We are conscious that the perceived quality and usefulness of a literature review-and reader confidence in its conclusions - is connected to the quality of the papers upon which the review reports. In the case of this particular review, our goal was to map the major knowledge claims about preparation that were contained within the broad body of research that sits around discussions of the link between teacher education and diverse learners and not to focus (from the beginning) on a subset of that research or to decide, in advance, that we could predict the topics that were most important. This led us to keep in the review all 209 papers that met the search criteria. However, we recognized that this would not allow us to provide the reader with detailed discussion of the features of each paper, a scenario which could reasonably lead to readers asking questions about the quality of the papers being reviewed. Our first step towards ensuring the quality of the included papers was the application of peer review as an inclusion/exclusion criterion. As a further measure, during Phase 1 of the research we drew upon the American Educational Research Association’s “Standards for reporting on empirical social science research in AERA publications" (American Educational Research Association, 2006). We reviewed abstracts and (where necessary) full papers to ensure that all included papers met two overarching criteria:

- warranted; that is, that they contained adequate evidence to justify the results and conclusions; and,

- transparent; that is, that their reporting made explicit the logic of inquiry and activities that led from the development of the initial interest, topic, problem, or research question; through the definition, collection, and analysis of data or empirical evidence; to the articulated outcomes of the study (American Educational Research Association, 2006).

Both of these criteria are, of course, open to interpretation and we acknowledge that other people analyzing the same body of work may find reasons to dispute these conclusions. However, the 
three lead authors conducted this evaluation independently and reached $100 \%$ agreement. No papers were excluded during this process, suggesting that peer review is a valid predictor of paper quality.

\section{Thematic Coding Process: Phase 2}

Phase 2 of the coding process was conducted to address Research Questions 2 and 3. Our coding was thus designed to make explicit:

- knowledge claims made about content, pedagogies, course/program structure, or overarching aims of ITE programs that the authors identify as well suited for preparing teachers for diverse learners; and,

- factors identified as constraining for teacher educators seeking to prepare future teachers to work with diverse learners.

The Phase 2 coding process was cyclical, iterative, and inductive, taking place over 9 months between January-September 2019. Three chief investigators began the coding process by reading the first 20 included papers' titles and abstracts to identify arguments made, or conclusions reached, in regard to our research questions. These 20 papers (indicated with \#\# in supplementary materials Table S1—online only) were checked for variety in terms of three factors: location of the study, research design, and specific diversity referents being discussed. With our research questions at the forefront of our mind we focused on identifying "repeating ideas" and "similarities and differences" relating to the included papers (Saldaña, 2016). Through this initial analysis of our subset of 20 papers, all three coding team members agreed that the papers focused consistently on two issues:

- Issues of ITE diversity content: what content teacher education should cover (in order to prepare teachers for various understandings of diverse learners); and 
- Issues of ITE delivery relevant to diversity: how should teacher education programs be designed or delivered to ensure that future teachers learn the required content and then act in ways that are appropriate for supporting the learning of diverse students?

Working with these two starting codes we then began the process of developing more fine-grained codes to capture any different ways in which the broad categories of content or delivery were discussed in order to "provide additional depth and insight into the category" (Parsons et al., 2017, p. 214). This involved a further period of rereading the 20 sample papers. The three chief investigators leading the systematic review made note of potential subcodes, brought these to team meetings, discussed the significance of these subcodes (relative to our research questions), and considered whether any proposed code/subcode was sufficiently differentiated from the others to make a justifiable inclusion to the coding framework. We negotiated the naming of these categories and tracked our work on a secure Excel spreadsheet housed on the online data storage site Cloudstor. As is common in the coding of qualitative data, some of our early codes remained largely unchanged through the entire coding period; some initial codes were subsequently removed or renamed, some were broken down into small sections, and some were grouped together in different ways at different times in the process (Clarke et al., 2014).

Through this process our original codes were expanded to five codes that advanced:

1. Arguments concerning the knowledge about diversity needed in ITE;

2. Arguments regarding the knowledge about teaching to diversity needed in ITE;

3. Examples of some specific ways that ITEs/ITE programs go about the work of teaching preservice teachers "about" and "catering to", including (a) examples of and challenges to "good/successful pedagogies" for teaching about diversity; (b) benefits of specialist or purpose-built courses; (c) papers focusing on partnerships between ITE providers; (d) papers focused on partnerships with other groups/organizations (including but not limited 
to schools); and, (e) failures in teacher education. We note here that this code was not directly related to the research questions considered within this paper and will be addressed within a separate publication. We reference it here (and in Supplementary Table S1) as a resource for readers interested in this specific dimension of the literature.

4. Arguments regarding challenges/difficulties relating to ITE students' beliefs or background that need to be overcome; and,

5. Arguments regarding challenges/difficulties relating to (a) the context for an ITE program; (b) the beliefs or background of teacher educators themselves; and, (c) the skills and knowledge of teacher educators.

In the process of reading and rereading these papers we identified another significant way in which some papers differed from others: a way that cut across different codes. In the most general sense this difference concerned the rationale the authors provided (implicitly or explicitly) for focusing on links between student diversity and teacher education in the first place. Although most papers expressed what might be thought of as a liberal interest in ensuring that all students had access to teachers who were committed to the provision of quality educational opportunities, some papers were much more explicit than others in terms of arguing that this is complex work that requires a commitment to identifying, addressing, undoing, and ultimately transforming educational and social systems. These papers were distinguishable from others in our subset due to their overt use of language and terminology associated with antiessentialist perspectives on difference and identity (ideas discussed in the introduction), and because of the references that were made to education as a vehicle for social justice. In other words, these papers saw "preparation" as involving much more than the acquisition of either "diversity facts" or "diversity strategies". Preparation, in these papers, was tied to the development of detailed, theoretically informed knowledge claims and understandings that the 
way diversity is understood directly impacts upon how teachers work. To capture the papers with this overtly transformative agenda we added a sixth and final code to our code sheet:

6. Papers marked by an overt commitment to social justice and social transformation through education: evidenced through significant engagement with social/cultural theories relating to justice, difference, and identity.

As each code was identified and given a working title, the authors, following Parsons et al. (2017, p. 214), developed a set of definitions/explications of the features of papers that matched each code and summarized these in our final coding sheet (see Table 3).

The three lead chief investigators for this paper then tested the coding framework by reading the full text of the next 20 included papers (marked in supplementary materials Table S1 with $\left.^{\wedge \wedge}\right) .19$ out of the 20 papers were coded the same by all three lead authors. To resolve the one exception, the authors reread the full text of the paper and agreed upon the final codes. These discussions also allowed us to reach agreement on two further points: first, we needed to recognize the potential for any single paper to relate to multiple codes; second, the initial coding of the $20+20$ papers had allowed us to reach conceptual saturation: a state achieved when researchers can identify no new codes relative to their research questions (Dixon-Woods, 2016). Working with this coding sheet, the lead author of this paper then read the full text of all 209 papers to complete the coding. As a final step to ensuring the validity of the coding, the other two chief investigators involved in coding selected a random sample of papers that were identified by the lead author as belonging to Code 1,2 , and 6 . They consulted the full paper, used the coding sheet to assign their own codes, and then looked for any points of disagreement with the coding of the first author. This process revealed $100 \%$ agreement. 


\section{Acknowledging our own Positions as Researchers and Coders}

As researchers with a long-standing commitment to the pursuit of educational and social justice we feel it important to pause here and acknowledge that the questions and the methods described above — along with the analysis and argument that follows below—are inevitably shaped by our own ideological positions. We share with Adams et al. (2016) the belief that "people in both dominant and subordinate groups have a critical role to play in dismantling oppression and generating visions for a more socially just future" (p. 14) and recognize the central role that education plays in this endeavor. With Freire (1998/2001), we reject the possibility of a neutral education, and argue that all those involved in any form of teacher preparation have a responsibility to do all that we can to recognize, denaturalize, contest and move beyond educational and social practices that reinforce and re-inscribe patterns of inequity and disadvantage. This includes looking critically and carefully at the knowledge base that underpins the decision making of teacher educators. Questions relating to what teacher educators should be able to know, and do, have, of course, been asked within teacher education literature before (Goodwin, et al. 2014; Loughran, 2014; Ryan et al., 2019). In this review, however, we approach the general question of teacher educators' knowledge with a sharp and specific focus on identifying (and illustrating in meaningful depth) the various types of knowledge claims about preparation and diversity that underpin our research in this field. This, we believe will ultimately improve the ability of teacher educators to work towards education as the practice of freedom (Freire, 1998/2001).

In pursuing this agenda we acknowledge that while it is not possible for us (or, indeed, any other researcher) to act as the completely disinterested interpreters of data, there is, nevertheless, much that can be learnt from a carefully documented analysis of an underexamined body of literature that draws upon our existing expertise without compromising on matters of procedural rigor. This review therefore combines elements of two different 
approaches to systematic reviews described by Dixon-Woods (2016): the authorship approach which sees a review as involving the application of expertise and scholarly sensibility gained over time; and the contractual approach which emphasizes the procedural nature of a review process to ensure that the search itself can be replicated by others. This, we argue, allows us to make a unique contribution to the field of teacher education. Our immersion in literature/debates related to diversity and teacher education gives us the ability to recognize patterns in the literature and to identify unusual/novel/unexpected responses. Our commitment to documenting the process of our search and analysis also ensures that the process can be replicated by others: a key feature of quality systematic reviews.

Our familiarity with the field of inquiry has a further (related) implication that must also be acknowledged: it has allowed us to develop codes that are sufficiently nuanced to capture differences between paper foci that may appear to be very similar, but which actually reflect very different ideological positions. This comes with the practical implication referenced above: some concepts and positions are more difficult to illustrate than others. Demonstrating the ways one position builds upon, extends, or departs from another takes time (and in an article) literal space. As the goal of this paper - and our claim to originality — is to provide as detailed a mapping of the literature as possible, we needed to accept from the outset of this process that some parts of our analysis would occupy more space than others. The different amount of space devoted to each question does not, therefore, signal any belief about the relevant significance of each question. Rather, it reflects our commitment to achieving our stated goals. Guided by Alexander (2020) we offer the reader the kind of "in-depth analysis" that allows us "not only to chronicle what is present or absent within the literature but also to unveil what discrepancies or ambiguities seem to exist. In essence, it is through such probing that the truly meaningful outcomes of the literature review are revealed" (p. 19). 
We turn now to the results of our analysis and the findings relating to each of our research questions. To ensure our interpretations are appropriately justified, we illustrate each claim that follows with specific in-text references to and quotations from a minimum of three illustrative papers. The quotations selected are those that we regard as "fit for purpose"; thus, most illustrative of the point we wish to make. Where more than one quotation is provided, our examples are taken from different countries or states, and relate to different diversity referents. In relation to Research Questions 2 and 3, these in-text references are followed by links to tables that provide illustrative examples from a set of 10 papers.

\section{Results}

\section{Groups of Learners Most Commonly Referenced in Literature: Links Between Teacher Education, Student Diversity, and Various Forms of Educational or Social Risk and Implications for Teacher Education Linked to These Forms of Risk}

We noted in the introduction a dramatic upturn of interest in the phenomenon of diverse learners within educational policy and associated debate. Table 2 shows that, within the papers included in this literature review, some of the key terms associated with diversity in its broadest sense are discussed more frequently than others, with cultural diversity, linguistic diversity, inclusive education, special education, disability, and socioeconomic status being the most frequently referenced. This is, perhaps, not surprising given that some groups have been the center of government policies and educational research for longer than others, with research relating to disability, for example, extending over many decades. By contrast, relatively few papers were focused on gender, sexuality, urban/rural disadvantage despite the (somewhat ironic) fact that the articles which $d o$ have this focus clearly illustrate the ongoing impact of these factors on students' lives (e.g. Francis, 2017; Miller, 2018; Zacko-Smith, 2010). In practical terms this uneven focus means that when teacher educators turn towards teacher 
education research for advice on how to approach the challenge of preparing future teachers for particular forms of diversity there is more research relating to some groups than others: a finding that is clearly relevant to the persistent patterns of educational success and failure referenced in our introduction. Questions about the source of the imbalance-how it has come into existence, why it persists, whether or not there are factors that motivate or discourage teacher educators from conducting research into particular manifestations of diversity and how or why some differences rise or fall in prominence (we are thinking specifically here of a declining interest in the links between gender and education) are beyond the scope of this review itself, but provide an important agenda for future research.

A number of the papers $(n=61)$ indicated via their titles, keywords, or abstracts an intention to focus on combinations of difference, such as inclusion and ethnicity, linguistic and cultural diversity, or socioeconomics and cultural identity-combinations which reflect growing awareness that groups are characterized by differences and that no population is truly homogenous (Azano \& Stewart, 2016; Miller, 2018; Robertson et al., 2017).

Regardless of whether the paper was focused on multiple or single diversity referents, each paper included in the review reflected the following claims about the links between diverse students and teacher education:

1. Diversity (in both student and community populations) is a fact of contemporary life;

2. Diversity makes new, and/or increased, and/or difficult demands on today's (still largely homogenous) teaching population which therefore requires particular or further forms of support/preparation; and,

3. Teacher educators have a major responsibility for ensuring future teachers are as prepared as possible to work effectively and respectfully with the entire student population. 
We illustrate each of these claims here with reference to a range of papers taken from diverse contexts and focused on different referents of diversity.

With respect to the first knowledge claim, Brooks and Houston (2015) noted that "Most preservice teachers enter classrooms in which students are culturally, ethnically, and linguistically diverse" (p. 114). Dao et al. (2018) linked "the increasingly cultural and linguistic diversity in education" (Knowledge Claim 1) to the conclusion that "teaching multicultural education for pre-service teachers becomes an important part of teacher education" (p. 55; Knowledge Claims 2 \& 3). Murdock and Hammel (2016) proceeded from the belief that "With the changing demographics of classrooms" (Knowledge Claim 1), "preservice teachers must be prepared to provide a just and equitable education for all students" (p. 85; Knowledge Claims 2 \& 3). The Murdock and Hammel (2016) paper also illustrates how authors often link recognition of diversity in a population to acknowledgement that diversity has often been synonymous with risk, marginalization, and patterns of educational success and failure, not because of any inherent failing of particular groups of students, but because of the ways in which teachers do, or do not, work with/for these groups. For example, Brown and Rodriguez (2017) also argued that "many ... predominantly white and middle-class teachers are unprepared to teach an urban public school population increasingly comprised of low-income children of color" due to "lack of cultural competencies, low expectations of and lack of caring for students, and racial/ethnic, linguistic, and class biases" (p. 75).

The first point we make about the literature, therefore, is that teacher education research contains a clearly stated interest in recognizing and responding to the needs of so-called diverse populations. There are, however, some groups who garner more attention than others and, as a result, there are differences in terms of populations or groups who are the subject of sustained attention. Identifying the explicit reasons why teacher educators do, or do not, place some groups at the center of their analysis requires further empirical research; a point we revisit in our 
discussion. The next question, of course, is what teacher educators are asked to do with this knowledge about the apparent facts of diversity. This brings us to Research Question 2.

\section{Claims Made About How Teacher Education Can Prepare Future Teachers for Diverse Learners, Specifically in Regard to Advice Concerning the Aims and Content of Teacher Education Courses/Programs}

We note at the outset of this discussion that our coding drew attention to advice relating to aims and content of teacher education and also to pedagogical approaches and course work design issues (including those relating to placements and other community-based experiences. In this review our focus is on the foundational claims about the purpose (aims) of teacher education and associated beliefs about the kinds and forms of knowledge that teacher education needs to reflect. This is knowledge that sits underneath, or comes before, decisions about pedagogy, assessment or program design and is thus the focus of this paper. Our analysis revealed three different ways in which the papers in this review framed and discussed what it means to prepare teachers to work with diverse learners; or three different knowledge claims:

1. By asserting the existence of a knowledge base about diversity (largely concentrating on demographic/population facts and the ways these groups have been historically at risk of educational alienation or failure) that future teachers need to possess;

2. By outlining frameworks, pedagogies and practices associated with catering to these identified forms of diversity that future teachers need to be able to display; and,

3. By highlighting the broader socio-critical and socio-political affordances of teacher education in relation to interrogating, problematizing, and reimagining diversity for social justice.

We illustrate these patterns, and associated knowledge claims, in the sections below with quotations from selected papers. These quotations are intended to work in combination: they 
first demonstrate the features of one particular set of papers, but when the discussion of research question 2 is read as a whole, the quotations also help to illustrate the differences between papers that are focused on teaching about, catering to, or teaching for diversity. Further examples of each theme are provided in Table 4. As noted above, illustrating these patterns and knowledge claims requires careful description and multiple references to the relevant papers and thus our response to Research Question 2 occupies considerable space in this manuscript.

\section{The Need to Provide Preservice Teachers with Knowledge About Diversity}

One hundred and ninety of the 209 included papers argued that in order to be able to work effectively with particular groups of learners, teachers need a detailed understanding of what are often presented (within this literature) as facts associated with these various forms of diversity; what we will now refer to as knowledge about diversity.

Papers in this subset had two key features: first, they make explicit mention of a particular form of diversity (often using percentages or population references to indicate the large numbers of students who belong to a particular group) and then go on to identify educational or social problems related to this form/rate of diversity that teachers need to know about. Second, papers focused on teaching about diversity, argue that there are particular (knowable) facts about an identified, at-risk group of learners (including, it is important to note, facts about educational/pedagogical frameworks commonly link to the successful education of these groups) that teachers need to possess in order to work effectively with these learners; knowledge that needs to be included in teacher education programs.

The paper by Alvarez Gutiérrez (2013) begins with reference to a particular form of diversity (Latino children in the United States who are part of mixed-status families-i.e. families with at least one parent who is an unauthorized immigrant) and then identifies a specific problem encountered by those children and their families: persistent and rising anti-Latino immigration policies. They reference the introduction of "over 1,600 antiimmigrant bills in 2011 
originating from all 50 states in the union" (p. 170); demonstrate that these laws have relevance to the "one in 10 children living in the United States" who are part of "mixed-status families" and argue that: "a majority of Latino children (regardless of immigration status) in classrooms across the country are impacted by anti-Latino immigration policies" (p. 170). From this basis the authors argued that teacher education programs need to ensure future teachers have sufficient knowledge of this situation: "teacher education students and professional educators should be trained and provided professional development to be zealously knowledgeable and recognize how anti-Latino immigration discourses spill into the education profession and how these are interconnected with local and school politics" (Alvarez Gutiérrez, 2013, p. 169).

This pattern is also illustrated in the paper by Acquah and Commins (2013). Focusing on the issue of cultural diversity and located in Finland, the authors began with a recognition of rates of diversity, and argued that this creates a problem if the teacher workforce is homogenous:

As student populations across Europe become more diverse, it is critical to understand and build on lessons already learned regarding teacher preparation. Pre-service teaching candidates in teacher education programmes have been found to be increasingly homogeneous - primarily White, middle class and from the dominant culture (p. 445).

The authors go on to argue that teacher education needs to increase future teachers' knowledge about a "mismatch between teachers' and students' cultures" (p. 445) in order to ensure that they graduate with "the confidence and preparation to address issues regarding the education of students from diverse backgrounds" (p. 445).

The paper from Kang and Martin (2018), based in Korea, provides a third example. The authors focused on disability to identify a problem: that "students with disabilities tend to underperform relative to peers without disabilities on assessments and that this gap in achievement tends to widen over time" (p. 320). From this basis the authors demonstrated that 
"Inclusive education (IE) has the potential to improve special education needs (SEN) students' learning outcomes, but IE requires teachers receive adequate training to be effective" (p. 319). The paper goes on to discuss:

the need for transforming pre-service teacher education using university-based experiential learning courses that simultaneously offer SEN students targeted, high quality content learning experiences that could also have a positive impact on SEN students' attitudes about and achievement in science (p. 319).

These three examples illustrate the broad features of papers concerned with teaching preservice teachers about diversity. They identify a group at risk and emphasize the need for teachers to develop new knowledge about that group. We will demonstrate below that these knowledge claims are often linked to specific suggestions about pedagogical approaches that will allow future teachers to cater to diversity in the future. Here our focus is on demonstrating the way the majority of the papers in this review name a group of learners with consistently evidenced educational problems that pre-service teachers need to know about in order to be effective teachers into the future. Further evidence of the ways in which other papers follow this pattern is provided in supplementary materials: Table S2 (online only) which include lengthy extracts from a further 10 papers illustrating research conducted in different locations, and in studies focused on various forms of diversity. We turn, in the next section, to illustrating an equally strong emphasis on ensuring that this knowledge can underpin action.

\section{Principles, Pedagogies, and Practices Catering To Diverse Learners}

One hundred and eighty-seven of the 190 papers that considered what teachers need to know about diversity also considered what teachers need to be able to do with this knowledge in order to cater to diversity in various educational contexts. These papers also make explicit mention of a particular form of diversity, often using percentages or population references to 
indicate the large numbers of students who belong to a particular group, and they identify a link between membership of a population subgroup and either educational or social risk.

From this basis, papers which we coded as focusing on teaching to diversity argue that there are particular (knowable) facts about how teachers can cater to diversity that teachers need to possess in order to work effectively with these learners. This claim is illustrated in various ways, including assertions re the need for new/specific teacher practices, references to pedagogical frameworks that will help future teachers to cater to diverse learners, and discussion of specific pedagogies/pedagogical skills/relationship or partnership skills that will help future teachers to cater to diverse learners (and their communities). Woven through these various claims are common arguments that teachers/preservice teachers currently lack the necessary pedagogical and partnership knowledge and skills; claims that are sometimes linked to evaluation of the effectiveness of various teacher education programs or courses.

For example, the paper by Alvarez Gutiérrez cited above as an example of teaching about diversity also demonstrates a commitment to catering to diversity, with the author referencing specific pedagogical frameworks or philosophies of teaching or pedagogical practices that could help future teachers cater to diversity: "I urge teacher education programs, professional development, school leaders, and educators to incorporate the following calls to action in the philosophy and practice of the profession...critical self-reflection...family engagement...civic engagement...participatory action research” (Alvarez Gutiérrez, 2013, p. 175).

A concern with ensuring teachers can cater to diversity is also illustrated by Qin and Villarreal (2018). Writing about rural education in China, the authors began with a problem:

In the last 30 years, these social and economic disparities have resulted in a large achievement gap between urban and rural schools .... This achievement gap continues to grow (p. 2).

They then posited a solution that is linked to the specific pedagogical framework of culturally relevant pedagogy and emphasized the positive impact of specific pedagogical 
strategies on at-risk learners, including, "multiple instructional strategies to address individual student needs" and "daily teaching plans” (Qin \& Villarreal, 2018, p. 10).

A third example of this pattern is provided by Broomhead (2013). Focused on special education in the context of the United Kingdom, the author identified a concern with respect to the skills of teachers regarding working with children with special education needs (SEN) and, as well, their families:

Focus on preparing pre-service teachers to support children with SEN has coincided with concerns regarding how they are ill-prepared for working with the parents of these pupils and are not equipped with the socio-emotional skills required to form effective home-school relationships (p. 174).

She went on to identify specific skills that need to be addressed by teacher educators, arguing that current lack of skills:

places pressure on teacher educators to address home-school collaboration during preservice teacher education. This is of increased importance within a SEN context, due to the additional support required by pupils with SEN involving parental input and collaboration, and consequent further communication between parents of children with SEN and teachers (Broomhead, 2013, p. 174).

Once again, we provide these three in-text examples as introductory illustrations of the theme, teaching to diversity. Further examples are included in the supplementary materials Table S3 (online only); examples drawn from a range of contexts, exploring various diversity referents.

Papers which explored issues relating to a knowledge base about diversity, and pedagogies and practices catering to diverse learners, constitute the majority of the papers included in this review. There is, however, a noteworthy third cluster of papers that we turn to now. 


\section{Affordances of Teacher Education in Regard to Teaching For Diversity}

As we explained above, some of the papers in this review are distinguishable from others because of more overt and sustained engagement with theoretical resources associated with what we describe as anti-essentialist perspectives on diversity. Although these papers generally also share some of the features associated with the two themes discussed above, the claims made within this third set of papers - a smaller subset of 40 out the 209 included — are based upon and justified through reference to what has been described as theoretically specific scholarship (Hytten \& Bettez, 2011, p. 16): specialist theoretical literature associated with each category of diversity. This includes, for example, anti-essentialist commentaries on gender that draw upon feminist or pro-feminist theory; analyzes of race that draw on resources associated with postcolonial theory or critical race theory; discussions of disability that acknowledge the differences between medical or social models of disability; and so on. These are papers that we describe as teaching for diversity.

Although the papers differ in structure and focus, they are recognizable due to the key features listed and illustrated below: clearly stated transformative aims, discussions of diversity that reflect anti-essentialist theoretical frameworks, explorations of the need for/value of ensuring future teachers engage with "specialist" knowledge relating to diversity, and demonstration of the links between specialist knowledge (or theory) and practices that can support educational transformation. We illustrate these features briefly here and expand upon them through reference to 10 papers included in supplementary materials Table S4 (online only).

First, papers that consider teaching for diversity recognize and express an interest in providing quality educational opportunities for all members of the population, including those commonly understood as at risk of exclusion, alienation, or failure. What makes this subset of papers different from those referenced above, is that they go beyond liberal or neoliberal acknowledgements of individual's needs or rights towards an assertion that these rights can only 
really be met through a fundamental transformation of educational and social systems. Lynskey (2015), for example, argued that it is the responsibility of teacher education to prepare graduates who can fight "inhumanity" (p. 73). Similarly, Zacko-Smith and Smith (2010) wrote:

"Educators are understood to be either upholding the status quo or to be defining/redefining what is classified as "normal" in their classrooms, and thus in the larger society as well" (p. 3).

Berta-Avila and William-White (2010) noted the fundamentally political work of teaching: our goal is to prepare highly qualified and politicized teachers who will be change agents ... activist teachers who are working towards equity, access and social justice in low-income, culturally, and linguistically (LI/CLD) classrooms, schools, and communities (p. 400).

Further examples of papers that see the purpose of education as social transformation, not social reproduction, are provided in the supplementary Table S4 (online only). This activist, transformative stance is fundamentally tied to an anti-essentialist perspective on difference and identity; the second feature of these papers that needs to be acknowledged. Authors working with anti-essentialist resources argue that well-documented links between difference and disadvantage are neither natural nor inevitable, but rather socially constructed. In other words, differences are made to matter in various historical and social contexts in ways that draw attention to the operation and forms of power. These papers identify the particular (Eurocentric and phallocentric) knowledges and beliefs that have become privileged in educational systems that have been designed to ignore, silence, devalue, or "other" large sections of the population. To give three examples: Cobb (2018) used Bernstein's notion of regulative discourse to examine the way in which open educational resources socialize "teachers and their students into Western culture, values, and beliefs" (p. 15); Liu and Milman (2010) showed that it is not students' backgrounds, but rather other people's "assumptions and intolerance", that "build an inequitable atmosphere where students experience varying degrees of comfort and ability to focus on class 
goals" (p. 625); and, Bates (2011) drew attention to the meanings that become attached to rural students (in music contexts).

Anti-essentialist perspectives not only reject the perceived "naturalness" or "normality" of associations between diversity and deficit - they also encourage educators to critically reflect on and question claims that groups (e.g., women, or people from Mexico, or children with a disability) are essentially similar in nature and needs. In the papers included within this literature review, this perspective sees authors use various theoretical resources to highlight the way in which categories themselves shift and evolve so that concepts such as "sex" or “disability" become categories to explain, rather than explanations in and of themselves. For example: Zacko-Smith and Smith (2010) used queer theory to critically reflect on common, simplistic understandings of gender and assert that "sexual orientation and gender [are] concepts that are flexible and flowing, and not static and fixed" (p. 6); Liu and Milman (2010) drew on resources including critical race theory to "reflect upon and challenge the use of curriculum that maintains the status quo and silences the marginalized into assimilation" (p. 620); and, Naraian and Schlessinger (2017) highlighted the way the concept of disability has been redefined over time, moving away from "political, organizational, and epistemological foundations of special education [that] have resulted in schooling practices that have marked disability as tragic, undesirable, and incompetent" (p. 82).

Anti-essentialism is also illustrated through explicit reference to the important idea of intersectionality. This is seen in 10 of the 40 papers included in the code, teaching for diversity, with three examples provided here: Gilham and Tompkins (2016), writing about inclusive education in Canada, noted that "inclusion as special education often neglects the intersectionality of important diversity topics such as race, class, and gender of individuals with disabilities" (p. 6); Robertson et al. (2017), in the USA, advocated for "providing preservice special educators with opportunities to explore the intersectionality between disability and other 
aspects of diversity" (p. 355); and, Miller (2018), also in the USA, writing about gender identity, argued that a lack of intersectionality leads to "a flattening, unidimensional, and nonintersectional perspective of gender identity and delegitimizes those who do not ascribe to gender identity norms (p. 75). Again, further examples of anti-essentialist perspectives (and various ways in which this was evidenced in a range of papers) are provided in the supplementary material Table S4 (online only).

A further feature of papers included in this subsection is the commonly articulated understanding that specialist, theoretically informed knowledge associated with anti-essentialist perspectives on difference, and an associated understanding of the ways in which differences can intersect or combine to create hierarchies of risk or advantage, needs to be taught in teacher education. The dispositions and practices that flow from an anti-essentialist mindset are not developed through simple exposure to knowledge about diversity. Nor will the requisite skills be developed simply because future teachers have a well-intentioned desire to cater to diversity. Rather, these papers argue that educational transformation - a foundational tenet of teaching for diversity—requires teachers to develop very particular combinations of theoretically informed knowledge and skills, all of which rest upon supported and structured opportunities to learn how to recognize, make visible, critique, and work against traditional operations of power. These perspectives are illustrated in the papers cited above but we provide three further, illustrative intext examples of each associated argument here, and lengthier illustrations in the supplementary materials Table S4 (online only).

First, there is a clear awareness that there is more than one way to approach teaching about/to/for diversity and there is an explicit rejection of approaches to diversity education that attempt to "add in" or "value" or "accommodate" difference in ways that leave the fundamental structures and ideologies of education unchanged or unexamined. Often described as assimilationist in nature, these perspectives underpin many approaches associated with teaching about, or catering to, diversity that specialist literature has consistently evaluated as inadequate. 
Examples of this are provided by: Zacko-Smith and Smith (2010) who report on "the "melting pot' paradigm popular in the 1950 s and 1960 s, when the stated desire was to create homogeneity, 'sameness', and equality" (p. 5); by Smith (2009) who distinguished between the "multicultural festival" and "transformative" approach [which] weave a range of cultural perspectives throughout the curriculum. (p. 46); and, by Pimentel (2010) who also critiques the “'contributions approach,' wherein educators merely insert discrete ethnic heroes, holidays, and cultural artifacts into the already existing curriculum" arguing that "this approach alone fails to examine underlying asymmetrical relations of power that produce inequitable outcomes” (p. 51). Building on this rejection of surface, simplistic, "recognition/celebration" approaches to diversity, the second point about teacher knowledges/skills made within these papers is that it is not possible to provide teachers with a portable, one-size-fits-all "tool kit" of strategies that will lead to social transformation. Instead, there is a consistent focus on the need to develop in future teachers the skills and knowledge to act in theoretically and politically informed ways in whatever complex, unpredictable context they may find themselves. For example: Seltzer-Kelly et al. (2011) highlighted the importance of teachers being able to recognize and challenge structures which construct students as "the philosophical Other" (p. 5); Acquah and Commins (2015) argued for structured opportunities within which future teachers critically reflect on "issues of culture, power and privileges" (p. 790), noting the link between these opportunities and "changing corresponding behavior to incorporate more positive views of culturally diverse students" (p. 792); and, Naraian (2014) demonstrated that sustained, deliberate exploration of specialist theoretical resources will develop future teachers with the capacity to "go forth into troubled schooling systems and actively work against practices that perpetuate norms of dis/ability" (p. 2). Further examples of this perspective are contained in the supplementary Table S4 (online only). 
In addressing Research Question 2, we have outlined three qualitatively different ways in which the papers included in the review engaged with issues relating to diversity, risk, and teacher education. 190 of the papers focused on outlining what teachers need to know about diversity, with this knowledge presented in an uncontested and generally unproblematized manner; and, all but three of these papers also outlined an expectation that a body of knowledge about learners, when accessed, would shape decision-making and the work of teaching, showing that knowledge about diversity is commonly paired with claims about how teachers should teach. A much smaller number of papers, 40, also drew upon perspectives associated with critical, social, and cultural theory in their exploration of what teachers (and thus teacher educators) need to know, understand, and thus be prepared to imagine and do.

\section{Factors Identified as Constraining for Teacher Educators Seeking to Prepare Future Teachers to Work with Diverse Learners}

To this point in our analysis we have focused on identifying the knowledge claims within the literature regarding the forms of diversity that teacher educators need to pay attention to (Research Question 1) and ways teachers can best be prepared for this diversity (Research Question 2). The papers included in this review also contain various knowledge claims about factors linked to teacher education specifically, (and the social context generally) that can impact upon, limit, or in some way constrain the work of teacher educators as they strive to achieve their goals. In this section of the paper we identify and describe key features associated with the three most commonly cited constraints beginning with references to general contextual constraints and then focusing more explicitly on constraints that are directly encountered in teacher preparation.

\section{Contextual Constraints}

In common with papers discussed in other reviews of teacher education (e.g. Sleeter, 2012), many papers in this review made reference (often in their introductions, often quite 
briefly) to the impact that a particular political, policy or institutional context had on the work of teacher education. Sixteen papers dwelt on these contextual constraints at length. These papers made reference to (and commented critically upon) the neoliberal or conservative political environments that increasingly dictate the content and design of teacher education programs (Aronson, 2013; Chang, 2018; Gorski, 2012) and identified the small and/or declining amount of space allocated to the understanding of student diversity within teacher education programs (Assaf, 2010; Aronson, 2013; Gorski 2012). Brayboy (2009) noted that, in this context, teacher education programs have the potential to be "rigid, narrow, and unforgiving to different ways of engaging the world" (p. 4). And with a different, but related focus, Evans-Winter and Twyman Hoff (2011) demonstrated the ways in which the academic careers of teacher educators who are working in a social justice framework and also, themselves, seen as diverse, are impacted by university systems such as student evaluations. They argue that "cultural hegemony is institutionalized when white students are afforded the privilege to evaluate black female professors without academic departments and universities critically assessing the role that racism and sexism play in student feedback" (p. 461).

As an aside, we note here a documented theme in teacher education literature is the potential for schools and teachers to work against or undermine the objectives developed through critically informed teacher education courses. It would therefore be reasonable to expect that the attitudes of teachers or structures of schools would emerge as a topic when we considered constraints on the work of teacher education. This, however, was not the case. While we are reluctant to speculate too much about the reasons for this absence, it is appropriate to note that our systematic review involved search parameters that excluded those papers that did not have an explicit focus on teacher education. Thus, papers that might have been more specifically located in schools, or more substantially interested in school-based teacher education, were not picked up through our search strategy. 
While most papers acknowledged some form of constraint in passing, in a significant number of papers $(n=59)$ challenges or constraints were explicitly linked to the knowledge, beliefs and dispositions of two particular groups of people: pre-service teachers and teacher educators themselves. We turn now to consideration of these data.

\section{Challenges Linked to Preservice Teachers}

Thirty-seven papers focused on identifying, describing or measuring pre-service teachers'(PSTs) beliefs about diverse learners, and/or PSTs' beliefs about their own preparedness, or capability to work with this diverse cohort. While making pre-service teachers' beliefs visible is a common goal of teacher educators - particularly where those beliefs are inconsistent with a program's ideological foundations such as, for instance, a commitment to social justice - it is still important to recognize that this work is neither straightforward nor without its demands. Problematic, discriminatory, naïve or contradictory beliefs take multiple forms, and manifest themselves in diverse ways all of which can be experienced as constraints (especially when PST's are resistant to changing their beliefs), in that they influence how a teacher educator can approach a particular objective. Making beliefs visible is therefore an important part of any transformative teacher education agenda. At the same time, however, the anti-essentialist perspective we outlined above reminds us that it is not appropriate to assume that all PSTs will hold conservative or reactive or negative points of view: PSTs, like students in classrooms, are diverse. The papers linked to this theme, therefore, demonstrate that teacher education is always located in a specific context. For this reason, it is important to allocate time and space to making PSTs' beliefs visible and using this knowledge to shape their pedagogical practices. The importance (and the challenge) of uncovering the beliefs of pre-service teachers is outlined in papers that explored different geographic/political contexts and focused on beliefs/skills/confidence of different diversity referents. We offer three in-text examples here (from 3 different contexts), and a further 10 examples in Supplementary Table S5. 
Pecek et al. (2014) investigated "the initial beliefs of student teachers concerning the Roma population, Europe's largest ethnic minority” (p. 359), as expressed by students studying at the University of Ljubljana in Slovenia and the Teacher Training Faculty at the University of Belgrade in Serbia; Bannister-Tyrell et al. (2018) "surveyed 100 undergraduate teacher education students in a regional university in Australia" to explore their "self-reported perceptions of their knowledge about students with exceptional needs, and their competence to be effective educators of these students in an inclusive classroom" (p. 16); and, Brandes and Crowson (2009), writing in the context provided by the United States of America investigated "the association between socio-political ideologies of preservice teachers and their attitudes toward disability-related matters within schools" (p. 271). The ten additional examples with a focus on pre-service teacher beliefs, (contained in Supplementary Table S5) demonstrate a sense that much of the work associated with teacher education involves identifying, changing and improving the beliefs (and associated knowledge claims) of the future teacher workforce.

\section{Challenges to Learning Linked to Teacher Educators}

Twenty papers considered in depth the issues relating to teacher educators' expertise, confidence, beliefs, and/or knowledges and the way these might constrain efforts to prepare preservice teachers for diverse learners and diverse contexts. In some cases, these constraints were illustrated through descriptions of how potential barriers had been overcome; in others through reference to ongoing challenges. The majority of these papers argued the need for teacher educators to possess the same kinds of robust knowledge that they seek to develop in their students; positioning any possible lack of knowledge as a key constraint to be overcome. For example, writing in the United Kingdom, De Carvalho (2016) investigated the constraining nature of "science teacher educators' views on religio-scientific issues and their positions on the place of these issues within science teacher education and the science classroom" (p. 253); in the United States of America, Assaf et al. (2010) examined limitations associated with "teacher 
educators' perspectives about multicultural education in an elementary and middle school teacher preparation program" (p. 116); and, Wright (2016) argued that "Early childhood teacher education faculty [in the USA] must be prepared to support sexual minority students in confronting decisions about disclosing their sexual orientation in the context of practicum" ( $p$. 189) thereby identifying a potential way in which lack of knowledge could constrain teacher educators' work.

Both strands of argument draw attention to the ways teacher educators' knowledge and beliefs can shape what they do, how they do it, and how they evaluate the work of others. Both strands make reference to the importance of teacher educators learning "on the job" as seen, for example, in the paper by Florian (2012) who argued that "teacher educators needed opportunities for professional development that would support them in preparing new teachers for the demands of inclusive education" (p. 280).

Interestingly, however, while many papers attempted to measure/assess/evaluate the beliefs or skills of pre-service teachers, only two papers explicitly include an attempt to do the same thing in relation to teacher educators' beliefs, skills or knowledge base. D'Haem and Griswold (2017) argued that "Although teacher educators expressed strong concerns about teaching candidates to work with parents from diverse cultural and linguistic backgrounds, they voiced doubts regarding their own ability to educate students regarding families from different cultures" (p. 81). Rigoni et al. (2013) used preservice teacher portfolios to reflect on "the degree to which students integrated concepts related to teaching in urban schools: asset/deficit perspectives, connections with families, social justice, high expectations for student learning, and contextualized teaching and learning" (p.88) and used this analysis as a platform for reflecting on issues relating to the development of faculty staff skills.

Analysis associated with respect to Research Question 3, therefore, reveals a consistent acknowledgement, within literature, of the ways that teacher educators' work can be constrained. The largest amount of attention is given to preservice teachers' resistance to learning and shifting 
their deficit mindsets towards diverse learners. While we see nothing surprising in the identification of attitudinal shift in pre-service teachers as a goal for teacher education (changing/challenging/broadening beliefs is a foundational objective for many working in the pursuit of educational justice and one that teaching for diversity explicitly recommends) it is interesting to note the attitudes/beliefs of teacher educators are not subjected to the same amount of scrutiny. In the context outlined at the beginning of this paper- the persistent failure of teacher education to prepare teachers confident in their own abilities to work with heterogeneous learners - this raises questions that warrant further consideration.

\section{Discussion}

This review has multiple implications for those working in teacher education. It has highlighted the complex and multi-layered nature of the concept of diversity as it is used within discussions that focus explicitly on the responsibilities of teacher educators to ensure that future teachers can meet the needs of diverse learners. Drawing on the findings of the review, we posit a tripartite definition to capture the major forms of advice found within literature that centers on what it means to prepare future teachers for teaching diverse learners:

1. Teaching about diversity: a focus which seeks to constitute the knowledge base about different types of diversity. This literature commonly offers facts and figures designed to illuminate the heterogeneity of a population. It includes details about rates and forms of diversity and highlights how forms of diversity influence educational access, experience, pathways, and outcomes. A focus on teaching about diversity is often related to questions regarding the curriculum of ITE.

2. Teaching to diversity: this focus outlines the assumptions that flow from claims regarding what we know "about" diverse learners, assumptions which relate to the kinds of skills, ways of knowing, pedagogies, and practices that teachers need to possess if they are to 
cater for, respond to, and differentiate for the diverse students in their context. A focus on teaching to diversity often relates to the curriculum of ITE and the pedagogies taught and modelled by teacher educators but also heavily invests in outlining the ways in which teachers should respond to diversity in decision-making associated with curriculum, pedagogy, assessment, and home/school partnerships.

3. Teaching for diversity connects with, but fundamentally goes beyond, an interest in recognizing and responding to the immediate diversity in a group of learners. Teaching for diversity relates to the affordances of teacher education as a political project in the identification, contestation, and/or denaturalization of narrow, reductive, essentialist beliefs about such concepts as mainstream/marginal and majority/minority, and underpins an advocacy for positions that take diversity as something to be normalized, celebrated, and valued.

In this discussion we point to three key findings relating to this tripartite definition that are significant for teacher educators who are concerned with the persistently uneven achievements of diverse students in schools. These key findings are that the literature is: (a) broad in scope but uneven in the amount of attention devoted to the various groups; (b) broad in interpretation of diversity but narrow in its engagement with theoretically specialist literature; and, (c) relatively silent on issues relating to the skills and knowledge of teacher educators themselves in regards to topics of diversity and teacher preparation.

We begin with the first of these points. All of the papers reflect a desire to ensure that graduating teachers have the knowledge and skills necessary to allow them to work successfully with all learners. This is consistent with what might be thought of as a liberal interpretation of concepts such as equity or justice. However, some groups of learners are more commonly acknowledged than others. The majority of the papers focus on issues relating to disability or cultural/ethnic identity. As the analysis has shown, considerably less attention is given to 
consideration of issues relating to sexuality or gender, or intersectionality, a concept which features prominently in the specialist literature associated with queer and contemporary feminist writings. In other words, the literature is broad in scope, but uneven in the amount of attention devoted to the various groups commonly recognized as either diverse or at risk. This highlights the risk that some groups are more likely to benefit from the work of teacher education than others. Indeed, there is almost a sense that only those at the top of an implicit "risk hierarchy" are going to be addressed extensively within the curriculum of teacher education. This has clear implications for the preparedness of teachers to work with multiple, and intersecting differences. Second, the papers captured by this review are broad in their interpretation of diversity (i.e., there are many ways to be recognized as diverse), but they are narrow in their engagement with what we (following Hytten \& Bettez, 2011) have referred to as the specialist literature associated with all of the various referents for diversity. There is, for example, relatively little engagement with the writings associated with feminist, postcolonial, or queer theory. This is not to suggest that literature focused on teaching about, or catering to, diversity that may not use these theoretical resources is not important. Rather, we argue that to achieve maximum impact, this literature needs to be augmented with an understanding that comes from engagement with the literature that has focused explicitly on getting beyond simple understandings of diversity to more in-depth, nuanced, complicated insights of the kind illustrated in Table S4 (online only). We argue that this literature-more commonly found within research focused on education rather than teacher education - needs to be consulted if we are to respond in substantial and research-informed ways to the diversity of modern populations. It is this literature that has looked at length and in depth at the origins and forms of inequity and which emphasizes the need to avoid essentialist, homogenizing representations and cultural appropriations. As the examples in Table S4 demonstrate, it is this literature that ultimately allow preservice teachers to recognize the operation of "power and privilege" (Acquah \& Commins 2013, p. 790); move beyond “dysconsciousness" (Cross et al., 2018, p. 142); “confront oppression” (Agbenyega \& Deku 
2011 p. 25); and, ultimately pursue transformative education. It is this literature, moreover, that provides us with the resources to consider issues of intersectionality and the way differences combine and interconnect to create particular, unique forms of risk or advantage. As a result, this is also the literature that can help teacher education programs go beyond tokenistic references to their support of diverse learners and social justice into the more demanding territories associated with educational and social reform. The persistence of patterns of educational success and failure referenced at the start of this paper means that the low number of articles that engage with specialist literature associated with what it means to conceptualize and pursue educational reform is problematic and warrants further investigation.

This brings us to our final point. Mapping major "programs" of research in teacher education over time, Cochran-Smith and Villegas (2015b) argued that teacher education research over the last century can be understood in terms of the questions it addresses and the issues it neglects. They argue for the importance of teacher education research looking more closely, in the future, at teacher preparation as a social practice, a focus which necessarily draws attention to the assumptions that underpin our research: the impact of researcher identity and positionality and the way theoretical frameworks and evidence are selected, deployed, and characterized. Central to this conceptualization of teacher education as a social practice is the dual recognition that the questions we ask as researchers are inevitably shaped by the intellectual resources we connect with and that these connections can directly impact upon the extent to which teacher education is genuinely able to meet the needs of the diverse preservice teachers who will be charged with meeting the needs of diverse learners into the future. Interestingly (and perhaps ironically, given the scrutiny of teacher education internationally), very few of the papers included in this review focused explicitly on issues relating to the skills and knowledge of teacher educators themselves in relation to either this challenge or the topic of diverse learners: a finding consistent with other papers that argue the need for enhanced investigation into the nature/beliefs/backgrounds of teacher educators. Some authors in this review argued 
passionately about the ways their practice is constrained by neoliberal agendas and the marginalization of social justice perspectives within teacher education programs. Several explored the impact of students' attitudes on their own work. But in the literature as a whole, little attention was given to how teacher educators' own knowledge base allows them to respond to this situation or, as we asked in the opening of this paper, to consider: how we can do better? There are many related questions that remain largely unaddressed in the literature; questions which we believe have significant potential to guide important, impactful research into the future.

For example: How or when do we, as teacher educators, critically evaluate our own preparedness to teach future teachers about diversity? By extension: How and where do we analyze the knowledge base we draw upon to design and then evaluate the effectiveness of our programs? How do we justify our aims and the sources of knowledge we draw upon? What forms of professional activity might enable teacher educators to develop agendas relating to teaching about/to/for diversity that are consistent with the goals of social justice and, thus, are fundamentally transformative in nature? How can leaders in teacher education create conditions within which it is safe for people to participate in conversations about the limitations of our knowledge base or skill sets? How do we get beyond the segregations and divisions that often characterize work in/around teacher education and which continue to separate those researchers who see themselves as concerned with "education" broadly, and those who investigate teacher education more specifically? And across all of those debates: How do we problematize what it is we think we know about preparing teachers to know about and cater to diversity, by looking at the outcomes of our work and its potential to contribute to education for diversity?

We argue that the literature as a whole lacks an explicit focus on ways of knowing and knowledge per se-an absence with serious consequences. Little attention is given to the ways that teacher educators select, access, reflect critically on, and evaluate various standpoints about diversity and select epistemic aims. This can mean that when teacher educators make decisions 
about how they are going to design programs or deliver courses, they are doing so without a critically reflexive stance that is based on the most recent, or most relevant, research-based advice (see Lunn Brownlee et al., 2017). Given the persistent patterns of educational success and failure we referenced at the start of this paper, we argue that this is a crucial absence. However, we need to go beyond simply engaging in critical reflexivity to include what Lunn Brownlee et al. (2017) describe as an epistemically focused reflexivity. Epistemic reflexivity would be evident when teacher educators engage in three related processes: discerning the diverse knowledges (e.g. the range of critical literatures) at their disposal and formulating epistemic aims (such as ensuring future teachers can justify their knowledge claims about diversity); deliberating about how this critical literature can be used to achieve these aims for preservice teachers in their specific context (e.g., critically evaluating various standpoints as well as personal and contextual conditions); and, dedicating action by designing teacher education programs that teach and assess the impact of these aims. Each step of this process is underpinned by epistemic cognition - robust ways of knowing.

We argue that it is only when teacher educators themselves engage in critical epistemic reflexivity (ways of knowing and doing) with respect to bodies of literature that center on critical consciousness (sources of knowledge) that a conceptual platform emerges which can address foundational questions about forms and consequences of inequity and the overall purpose of education. This double criticality, with respect to both specialist knowledge and ways of knowing, can support a new way of thinking about and enacting an epistemically reflexive pedagogy of teaching for diversity in teacher education. As our review has demonstrated, however, there is very little consideration within ITE literature about the ways teacher educators can learn to work reflexively. This is an area requiring significantly further research: and one that will be discussed in future papers linked to this review. 


\section{Conclusion}

We began this paper with the following acknowledgements. First, student populations across the world are characterized by diversity: diversity associated with factors such as gender, cultural, ethnic, and First Nations identities; sexuality; rurality; family form; and socioeconomics. Some manifestations of diversity are not new but have become more visible thanks to the advocacy of individuals and groups. Second, different forms and combinations of diversity have historically and consistently been linked to patterns of educational success and failure; not because of any inherent failings of a group, but because of the way meanings have been made to matter. Third, teacher educators have a clear leadership role to play in helping future teachers conceptualize and implement the kinds of educational interventions that have the greatest possible chance of creating new educational futures within which all learners have an opportunity to succeed. And fourth: to this point in time, our efforts to interrupt patterns of educational success and failure have been patchy at best and ineffectual at worst.

The review we have provided of literature associated with the links between teacher education and diverse learners suggests that teacher educators draw upon different kinds of intellectual and theoretical resources to conceptualize both their understanding of "the problems" related to diversity, and to formulate their responses. Currently, literature focused on teacher education and diversity concentrates largely on issues relating to teaching about and catering to diversity. Persistent patterns relating to student success and failure raise the possibility that we need to spend more time considering what it means to teach for diversity. Taking this argument forward requires teacher educators to have the capacity not only to identify different literatures, but to engage with this literature in confident ways. In other words, teacher educators need to be able to demonstrate critical epistemic reflexivity as we consider the extent to which we are focusing on teaching about, to, or for diversity. This critical epistemic reflexivity, we believe, could become the basis of a pedagogy of ITE — and, indeed, teacher education more broadly- 
and is essential if we are ultimately to identify, defend, and enact forms of teacher education that work for diversity and which, from this basis, might finally play more of a part to interrupt persistent, truly wicked, displays of educational disadvantage.

\section{References}

*indicates papers included in the dataset

*Acquah, E. O., \& Commins, N. L. (2013). Pre-service teachers' beliefs and knowledge about multiculturalism. European Journal of Teacher Education, 36, 445-463. doi:10.1080/02619768.2013.787593

*Acquah, E. O., \& Commins, N. L. (2015). Critical reflection as a key component in promoting pre-service teachers' awareness of cultural diversity. Reflective Practice, 16, 790-805. doi:10.1080/14623943.2015.1095729

Australian Institute for Teaching and School Leadership. (2017). National Professional Standards for Teachers. Retrieved from http://www.aitsl.edu.au/australian-professionalstandards-for-teachers/standards/list

Alexander, P. A. (2020). Methdological guidance paper: The art and science of quality systematic reviews. Review of Educational Research, 90, 6-23. doi: $10.3102 / 0034654319854352$

*Alvarez Gutiérrez, L. (2013). Costo Alto de Política Anti-imigrante Sobre la Familia y Educación 1 [The adverse consequences of anti-Latino immigration laws]. Theory into Practice, 52, 169-179.

American Educational Research Association. (2006). Standards for reporting on empirical social science research in AERA publications. Educational Researcher, 35(6), 33-40. doi:10.3102/0013189X035006033 
*Assaf, L. C., Garza, R., \& Battle, J. (2010). Multicultural teacher education: Examining the perceptions, practices, and coherence in one teacher preparation program. Teacher Education Quarterly, 37(2), 115-135.

Avramidis, E., \& Norwich, B. (2002). Teachers' attitudes towards integration/inclusion: A review of the literature. European Journal of Special Needs Education, 17, 129-147. doi: $10.1080 / 08856250210129056$

*Azano, A. P., \& Stewart, T. T. (2016). Confronting challenges at the intersection of rurality, place, and teacher preparation: Improving efforts in teacher education to staff rural schools. Global Education Review, 3(1), 108-128.

Banks, J., Cochran-Smith, M., Moll, L., Richert, A., Zeichner, K., LePage, P., ... McDonald, M. (2005). Teaching diverse learners. In L. Darling-Hammond \& J. Banks (Eds.), Preparing teachers for a changing world: What teachers should learn and be able to do (pp. 232274). San Francisco, CA: John Wiley.

*Bannister-Tyrrell, M. L., Mavropoulou, S., Jones, M., Bailey, J., O'Donnell-Ostini, A., \& Dorji, R. (2018). Initial teacher preparation for teaching students with exceptionalities: Preservice teachers' knowledge and perceived competence. Australian Journal of Teacher Education, 43(6), 16-34. doi:10.14221/ajte.2018v43n6.2

*Bates, V. C. (2011). Preparing rural music teachers: Reflecting on "shared visions". Journal of Music Teacher Education, 20(2), 89-98. doi:10.1177/1057083710377722

*Berta-Avila, M. I., \& William-White, L. (2010). A conscious agenda for cultivating future teachers' equity and social justice paradigms. Teacher Education \& Practice, 23, 399425.

Borgerding, L. A., Klein, V. A., Ghosh, R., \& Eibel, A. (2015). Student teachers' approaches to teaching biological evolution. Journal of Science Teacher Education, 26, 371-392.

*Brandes, J. A., \& Crowson, H. M. (2009). Predicting dispositions toward inclusion of students with disabilities: The role of conservative ideology and discomfort with disability. Social 
Psychology of Education: An International Journal, 12, 271-289. doi:10.1007/s11218$\underline{008-9077-8}$

*Brooks, B. R., \& Houston, S. (2015). Preservice teachers developing cultural competency: "We are more connected than we think". Global Education Journal, 2015(4), 114-138.

*Broomhead, K. E. (2013). 'You cannot learn this from a book'; Pre-service teachers developing empathy towards parents of children with special educational beeds (SEN) via parent stories. European Journal of Special Needs Education, 28, 173-186.

doi:10.1080/08856257.2013.778109

*Brown, T. M., \& Rodriguez, L. F. (2017). Collaborating with urban youth to address gaps in teacher education. Teacher Education Quarterly, 44(3), 75-92.

Burgess, C., \& Berwick, C. (2009). Aboriginal peoples' perceptions and beliefs about quality teaching. Paper presented at the AARE annual conference, Canberra.

*Castro, A. (2010). Themes in the research on preservice teachers' views of cultural diversity: Implications for researching millennial preservice teachers. Educational Researcher, 39, 198-210. doi:10.3102/0013189X10363819

Chang, I. S. (2008). Exploring and developing model of teacher curriculum for multicultural education. The Journal of Elementary Education, 21, 281-305.

Cheng, M., Tang, S., \& Chang, A. (2014). Differences in pedagogical understanding among student-teachers in a four-year initial teacher education programme. Teachers and Teaching: Theory and Practice, 20, 152-169.

Clarke, A., Triggs, V., \& Nielsen, W. (2014). Cooperating teacher participation in teacher education: A review of the literature. Review of Educational Research, 84, 163-202. doi:10.3102/0034654313499618

*Cobb, D. J. (2018). Placing the spotlight on open educational resources: Global phenomenon or cultural guise? International Education Journal: Comparative Perspectives, 17(3), 15-29. 
Cochran-Smith, M., Albert, L., Dimattia, P., Freedman, S., Jackson, R., Mooney, J., ... Zollers, N. (1999). Seeking social justice: A teacher education faculty's self-study. International Journal of Leadership in Education: Theory and Practice, 2, 229-253. doi:10.1080/13603124.1999.11509466

Cochran-Smith, M., \& Villegas, A. M. (2015a). Framing teacher preparation research: An overview of the field, Part 1. Journal of Teacher Education, 66(1), 7-20. doi:10.1177/0022487114549072

Cochran-Smith, M., \& Villegas, A. M. (2015b). Studying teacher preparation: The questions that drive research. European Educational Research Journal, 14, 379-394. doi:10.1177/1474904115590211

Cochran-Smith, M., Villegas, A. M., Abrams, L., Chavez-Moreno, L., Mills, T., \& Stern, R. (2015). Critiquing teacher preparation research: An overview of the field, Part II. Journal of Teacher Education, 66, 109-121. doi:10.1177/0022487114558268

*Colon-Muniz, A., Brady, J., \& SooHoo, S. (2010). What do graduates say about multicultural teacher education? Issues in Teacher Education, 19(1), 85-108.

*Dao, V., Farver, S., \& Jackson, D. (2018). Getting down to identities to trace a new career path: Understanding novice teacher educator identities in multicultural education teaching. Advances in Research on Teaching, 30, 55-72. doi:10.1108/S1479-368720180000030004

De Boer, A., Pijl, S. J., \& Minnaert, A. (2011). Regular primary schoolteachers' attitudes towards inclusive education: A review of the literature. International Journal of Inclusive Education, 15, 331-353. doi:10.1080/13603110903030089

*De Carvalho, R. (2016). Science initial teacher education and superdiversity: Educating Science teachers for a multi-religious and globalised Science classroom. Cultural Studies of Science Education, 11, 253-272. doi:10.1007/s11422-015-9671-y

Department for Education. (2011/2013). Teachers' standards: Guidance for school leaders, school staff and governing bodies. Retrieved from 
https://assets.publishing.service.gov.uk/government/uploads/system/uploads/attachment data/file/665520/Teachers Standards.pdf

*D'Haem, J., \& Griswold, P. (2017). Teacher educators' and student teachers' beliefs about preparation for working with families including those from diverse socioeconomic and cultural backgrounds. Education \& Urban Society, 49, 81-109. doi:10.1177/0013124516630602

Dixon-Woods, M. (2016). Systematic reviews and qualitative studies. In D. Silverman (Ed.), Qualitative research (4th ed., pp. 379-394). London, UK: SAGE.

*Evans-Winters, V. E., \& Twyman Hoff, P. (2011). The aesthetics of white racism in pre-service teacher education: A critical race theory perspective. Race, Ethnicity \& Education, 14, 461-479. doi:10.1080/13613324.2010.548376

Fields, J., \& Payne, E. (2016). Editorial introduction: Gender and sexuality taking up space in schooling. Sex Education, 16(1), 1-7.

*Flintoff, A., Dowling, F., \& Fitzgerald, H. (2015). Working through whiteness, race and (anti) racism in physical education teacher education. Physical Education and Sport Pedagogy, 20, 559-570. doi:10.1080/17408989.2014.962017

*Florian, L. (2012). Preparing Teachers to Work in Inclusive Classrooms: Key Lessons for the Professional Development of Teacher Educators from Scotland's Inclusive Practice Project. Journal of Teacher Education, 63(4), 275-285. doi:10.1177/0022487112447112

Francis, B., Mills, M., \& Lupton, R. (2017). Towards social justice in education: Contradictions and dilemmas. Journal of Education Policy. doi:10.1080/02680939.2016.1276218

Francis, D. A. (2017). Homophobia and sexuality diversity in South African schools: A review. Journal of LGBT Youth, 14, 359-379. doi:10.1080/19361653.2017.1326868

*Gilham, C. M., \& Tompkins, J. (2016). Inclusion reconceptualized: Pre-service teacher education and disability studies in education. Canadian Journal of Education, 39(4), 1-25. 
Goodwin, A. L., Smith, L., Souto-Manning, M., Cheruvu, R., Tan, M. Y., Reed, R., \& Taveras, L. (2014). What should teacher educators know and be able to do? Perspectives from practicing teacher educators. Journal of Teacher Education, 65(4), 284-302. doi:https://doi.org/10.1177/0022487114535266

*Gorski, P. C. (2012). Instructional, institutional, and sociopolitical challenges of teaching multicultural teacher education courses. Teacher Educator, 47, 216-235. doi: $10.1080 / 08878730.2012 .660246$

Groundwater-Smith, S., Ewing, R., \& Le Cornu, R. (2011). Teaching: Challenges and dilemmas. South Melbourne, Australia: Cengage.

Han, K. T., \& Laughter, J. (Eds.). (2019). Critical Race Theory in Teacher Education: Informing Classroom Culture New York: Teachers College Press.

Hofmann, M. E., Hinkel, J., \& Wrobel, M. (2011). Classifying knowledge on climate change impacts, adaptation, and vulnerability in Europe for informing adaptation research and decision-making: A conceptual meta-analysis. Global Environmental Change, 21, 11061116. doi:10.1016/j.gloenvcha.2011.03.011

Hollins, E. R., \& Guzman, M. T. (2005). Research on preparing teachers for diverse populations. In M. Cochran-Smith \& K. M. Zeichner (Eds.), Studying teacher education: The report of the AERA Panel on Research and Teacher Education (pp. 477-548). Mahwah, NJ: Lawrence Erlbaum Associates Publishers.

Hytten, K., \& Bettez, S. C. (2011). Understanding education for social justice. Educational Foundations, 25(1/2), 7-24.

Ives, J., \& Castillo-Montoya, M. (2020). First-generation college students as academic learners: A systematic review. Review of Educational Research, 90(2), 139-178. doi:https://doi.org/10.3102/0034654319899707

Kang, D. Y., \& Martin, S. N. (2018). Improving learning opportunities for special education needs (SEN) students by engaging pre-service science teachers in an informal experiential 
learning course. Asia Pacific Journal of Education, 38, 319-347.

doi:10.1080/02188791.2018.1505599

Keddie, A. (2012). Education for diversity and social justice. New York, NY: Routledge.

Kline, J., Soejatminah, S., \& Walker-Gibbs, B. (2014). Space, place and race: Ethics in practice for educational research in ethnically diverse rural Australia. Australian and International Journal of Rural Education, 24(3), 49-67.

Lautenbach, F., \& Heyder, A. (2019). Changing attitudes to inclusion in preservice teacher education: A systematic review. Educational Research, 61, 231-253.

doi:10.1080/00131881.2019.1596035

Liu, L. B., \& Milman, N. B. (2010). Preparing teacher candidates to teach diverse student populations through reflective practice. Reflective Practice, 11, 619-630. doi:10.1080/14623943.2010.516973

Loughran, J. (2014). Professionally developing as a teacher educator. Journal of Teacher Education, 65(4), 271-283. doi:https://doi.org/10.1177/0022487114533386

Lunn Brownlee, J., Ferguson, L., \& Ryan, M. (2017). Changing teachers' epistemic cognition: A new conceptual framework for epistemic reflexivity. Educational Psychologist, 52, 242252. doi:10.1080/00461520.2017.1333430

*Lynskey, A. C. (2015). Countering the dominant narrative: In defense of critical coursework. Educational Foundations, 28(1), 73-86.

Maged, S. (2011). Teacher education for cultural diversity. Bentley, WA, Australia: Curtin University.

Metcalf-Turner, P. (2009). Realizing the democratic ideal: A call for an integrative approach to inclusion of multicultural course content in teacher education programs. Teacher Education and Practice, 22, 464-467.

*Miller, S. J. (2018). Reframing schooling to liberate gender identity. Multicultural Perspectives, 20, 70-80. doi:10.1080/15210960.2018.1447067 
Mills, C., \& Ballantyne, J. (2016). Social justice and teacher education: A systematic review of empirical work in the field. Journal of Teacher Education, 67, 263-276. doi.org/10.1177/0022487116660152

Mills, C., Gale, T., Smith, C., \& Cross, R. (2019). Activist dispositions for social justice in advantaged and disadvantaged contexts of schooling. British Journal of Sociology of Education, 40, 614-630. doi:10.1080/01425692.2019.1582322

Ministerial Council on Education, Employment, Training and Youth Affairs. (2008). Melbourne declaration on educational goals for young Australians. Retrieved from http://www.curriculum.edu.au/verve/_resources/National_Declaration_on the_Educational Goals_for_Young_Australians.pdf

Moher, D., Shamseer, L., Clarke, M., Ghersi, D., Liberati, A., Petticrew, M., ... Stewart, L. A. (2015). Preferred reporting items for systematic review and meta-analysis protocols (PRISMA-P) 2015 statement. Systematic Reviews, 4(1), 1. doi:10.1186/2046

*Murdock, D., \& Hamel, E. (2016). I would quit my job: Unpacking preservice teachers' perceptions of culture and diversity. International Journal of Critical Pedagogy, 7(2), 85106.

*Naraian, S. (2014). Agency in real time? Situating teachers' efforts toward inclusion in the context of local and enduring struggles. Teachers College Record, 116(6), 1-38.

*Naraian, S., \& Schlessinger, S. (2017). When theory meets the "reality of reality": Reviewing the sufficiency of the social model of disability as a foundation for teacher preparation for inclusive education. Teacher Education Quarterly, 44(1), 81-100.

Opie, J. L. (2018). Through the eyes of secondary students with vision impairment : A phenomenological inquiry into inclusive schooling. Clayton, Vic., Australia: Monash University. 
Orlando, J., \& Harreveld, B. (2014). Democracy, critique, and the presupposition of knowledge: Teachers as capable, resourceful theorists. Asia-Pacific Journal of Teacher Education, 42, 321-323.

Pantic, N. (2015). A model for study of teacher agency for social justice. Teachers and Teaching: Theory and Practice, 21, 759-778.

Parsons, S., Vaughn, M., Scales, R. Q., Gallagher, M. A., Parsons, A. W., Davis, S. G., ... Allen, M. (2017). Teachers' instructional adaptations: A research synthesis. Review of Educational Research, 88, 205-242. doi:10.3102/0034654317743198

Payne, E. C., \& Smith, M. J. (2012). Safety, celebration, and risk: Educator responses to LGBTQ professional development. Teaching Education, 23, 265-285.

Pease-Alvarez, L., \& Thompson, A. (2014). Teachers working together to resist and remake educational policy in contexts of standardization. Language Policy, 13, 165-181.

*Pecek, M., Macura-Milovanovic, S., \& Vujisic-Živkovic, N. (2014). The cultural responsiveness of teacher candidates towards Roma pupils in Serbia and Slovenia--Case studies. Journal of Education for Teaching: International Research and Pedagogy, 40, 359-376. doi: $10.1080 / 02607476.2014 .929383$

Pegg, J. E., \& Reading, C. E. (2009). Embedding ICT in learning: Power in rural partnerships. In Society for the Provision of Education in Rural Australia 25th National Rural Education Conference Proceedings - Education in a Digital Present: Enriching Rural Communities (pp. 11-23). Osborne Park, WA, Australia: SPERA.

Petticrew, M., \& Roberts, H. (2008). Systematic reviews in the social sciences: A practical guide. Malden, MA: John Wiley \& Sons.

Pimentel, C. (2010). Critical race talk in teacher education through movie analysis: From "Stand and Deliver" to "Freedom Writers". Multicultural Education, 17(3), 51-56. 
Qi, J., \& Ha, A. S. (2012). Inclusion in physical education: A review of literature. International Journal of Disability, Development Education, 59, 257-281. doi:10.1080/1034912X.2012.697737

*Qin, L., \& Villarreal, E. (2018). Chinese pre-service teachers' perceptions of teaching practicum under contrasting contexts: Implications for rural teacher preparation. Australian \& International Journal of Rural Education, 28(2), 1-20.

*Rigoni, K. K., Pugach, M. C., Longwell-Grice, H., \& Ford, A. (2013). A programmatic view of portfolios for urban teacher preparation: A second look. Education \& Urban Society, 45(1), 88-119. doi:10.1177/0013124511408598

*Robertson, P. M., McFarland, L. A., Sciuchetti, M. B., \& García, S. B. (2017). Connecting the dots: An exploration of how pre-service special education teachers make sense of disability and diversity. Teaching and Teacher Education, 65, 34-47. doi:10.1016/j.tate.2017.02.020

Rosiek, J., Schmitke, A., \& Heffernan, J. (2017). Chapter 1: Queering teacher education curriculum: A case study of lessons learned in the transformation of a teacher education program. Curriculum \& Teaching Dialogue, 19(1/2), 3-17.

Rowan, L. (2018). Student diversity, education and social justice. In J. Allen \& S. White (Eds.), Learning to teach in a new era (pp. 243-247). Cambridge, UK: Cambridge Uni. Press.

Rowan, L., Kline, J., \& Mayer, D. (2017). Early career teachers' perceptions of their preparedness to teach "diverse learners": Insights from an Australian research project. Australian Journal of Teacher Education, 42(10). doi:10.14221/ajte.2017v42n10.5

Ryan, J., Jones, M., Buchanan, M., Morris, P., Nuttall, M., \& Smith, C. (2011). Effective preservice teacher education 'at a distance': An investigation of the multimodal delivery of a secondary preservice teacher education program -- perceptions of preservice teachers, teachers and university lecturers. In C. F. Macteer (Ed.), Distance education (pp. 149-166). New York, NY: Nova Science Publishers. 
Saldaña, J. (2016). The coding manual for qualitative researchers (3rd ed.). Thousand Oaks, CA: Sage.

*Seltzer-Kelly, D. L., Cinnamon, S., Cunningham, C. A., Gurland, S. T., Jones, K., \& Toth, S. L. (2011). (Re)imagining teacher preparation for conjoint democratic inquiry in complex classroom ecologies. Complicity: An International Journal of Complexity \& Education, 8(1), 5-27. doi:10.29173/cmplct9185

Sleeter, C. (2008). Preparing White teachers for diverse students. In M. Cochran-Smith, S. Feiman-Nemser, \& D. J. McIntyre (Eds.), Handbook of research on teacher education (3rd ed., pp. 559-582). New York, NY: Routledge.

Sleeter, C., \& Owuor, J. (2011). Research on the impact of teacher preparation to teach diverse students: The research we have and the research we need. Action in Teacher Education 33, 524-536. doi:10.1080/01626620.2011.627045

Sleeter, C. E. (2012). Confronting the marginalization of culturally responsive pedagogy. Urban Education, 47(3), 562-584. doi:10.1177/0042085911431472

*Smith, E. B. (2009). Approaches to multicultural education in preservice teacher education: Philosophical frameworks and models for teaching. Multicultural Education, 16(3), 45-50.

Wilhelmsen, T., \& Sørensen, M. (2017). Inclusion of children with disabilities in physical education: A systematic review of literature from 2009 to 2015. Adapted Physical Activity Quarterly, 34, 311-337. doi:10.1080/1034912X.2012.697737

Wonseok, C., \& Chepyator-Thomson, R. (2011). Multiculturalism in teaching physical education: A review of U.S. based literature. Journal of Research in Health, Physical Education, Recreation, Sport \& Dance, 6(2), 14-20.

Wright, T. (2016). On coming out in practicum: An autoethnography of (non) disclosure. Journal of Early Childhood Teacher Education, 37, 189-202. doi:10.1080/10901027.2016.1204572

*Zacko-Smith, J. D., \& Smith, G. P. (2010). Recognizing and utilizing queer pedagogy: A call 
for teacher education to reconsider the knowledge base on sexual orientation for teacher education programs. Multicultural Education, 18(1), 2-9.

Zschocke, K., Wosnitza, M., \& Bürger, K. (2016). Emotions in group work: Insights from an appraisal-oriented perspective. European Journal of Psychology of Education, 31, 359384. 
Table 1

Examples $^{\#}$ of Search Terms Used Across the Five Databases

\begin{tabular}{|c|c|}
\hline $\begin{array}{l}\text { Search term category } \\
\text { (joined with AND) }\end{array}$ & Search terms in abstract (joined with OR) \\
\hline Diversity referents: & $\begin{array}{l}\text { student diversity, diverse learners, diversity in education, ethnic } \\
\text { groups, cultural differences, ethnic diversity, minority groups, } \\
\text { multicultural education, minority students } \\
\text { low income, socioeconomic status, educationally disadvantaged, } \\
\text { access to education, academic accommodation } \\
\text { special needs, inclusive education, religion, sexuality, gender bias, } \\
\text { gender discrimination, gender stereotype } \\
\text { rural schools, rural urban differences, indigenous populations, } \\
\text { Aboriginal Australians, cultural background, family characteristics, } \\
\text { family structure, parent background }\end{array}$ \\
\hline School & student, learner, pupil \\
\hline Teacher education & $\begin{array}{l}\text { pre-service teacher education, teacher education, teacher educator, } \\
\text { teacher education programs, student teach* }\end{array}$ \\
\hline Implications & $\begin{array}{l}\text { teacher preparation, teacher effectiveness, teacher response, teacher } \\
\text { influence, teaching skills, prediction of teacher success, implication* }\end{array}$ \\
\hline \multicolumn{2}{|c|}{$\begin{array}{l}\text { \# All of the terms listed here were the exact terms used; we have labelled these as examples } \\
\text { because each database had slightly different terms in use, and there is insufficient space here to } \\
\text { reproduce all of the actual terms that were searched. We note that the term "race" is captured } \\
\text { (within the data bases we searched) by the terms "ethnicity, ethnic groups, ethnic minority, } \\
\text { minority students" } \\
\text { * The asterisk indicates truncation of search term, for example teach* included teacher, teacher } \\
\text { teaching, etc. }\end{array}$} \\
\hline
\end{tabular}


Table 2

Diversity Referents Summary

\begin{tabular}{|c|c|c|}
\hline Diversity referents & $N$ & Total \\
\hline Cultural & & 93 \\
\hline cultural & 45 & \\
\hline multicultural & 27 & \\
\hline ethnic/ethnicity & 13 & \\
\hline migrant, immigrant & 8 & \\
\hline Linguistic & & 33 \\
\hline Inclusion & & 33 \\
\hline inclusion (general) & 14 & \\
\hline inclusion (special education) & 5 & \\
\hline inclusion (disability) & 12 & \\
\hline inclusion (family background) & 1 & \\
\hline inclusion (social justice) & 1 & \\
\hline $\begin{array}{l}\text { Special education } \\
\text { special needs }\end{array}$ & 15 & 26 \\
\hline special education/educational needs & 11 & \\
\hline $\begin{array}{l}\text { Socioeconomic factors } \\
\text { socioeconomic diversity }\end{array}$ & 20 & 26 \\
\hline social & 2 & \\
\hline class & 2 & \\
\hline poverty & 1 & \\
\hline community & 1 & \\
\hline Race, racial & & 16 \\
\hline Rurality & & 13 \\
\hline Family, families & & 12 \\
\hline First Nations & & 5 \\
\hline LGBQTI & 4 & 5 \\
\hline Sexuality (queer) & 1 & \\
\hline Gender (binary) & 3 & 4 \\
\hline Gender (queer) & 1 & \\
\hline Religion, religious & & 5 \\
\hline
\end{tabular}


Table 3

Coding Table

\begin{tabular}{ll}
\hline Codes/Subcodes & \multicolumn{1}{c}{ Criteria for inclusion in this code } \\
\hline Code 1: & Characterized by: \\
About diversity & - arguments concerning knowledge about diversity needed in ITE \\
& Illustrated by: \\
& - focus on one or more signifier of diversity (e.g., gender, SES) or broad \\
& phenomenon of "diverse learners" \\
& - $\quad$ statistics/numerical data relating to demographics and achievement \\
& - $\quad$ exploration of specific knowledge or facts or figures relating to the \\
& selected signifiers of diversity teachers need to be aware of
\end{tabular}

Code 2:

To diversity

\section{Characterized by:}

- arguments regarding the knowledge about teaching to diversity in schools that needs to be covered in ITE

\section{Illustrated by:}

- claims about what PSTs need to be able to do in order to teach to, or work with, diverse learners and communities

- discussion of learning styles, learner needs, how to shape pedagogical

Code 3: choices, curriculum decisions, relationships with home/school/students

ITE structures $\quad-\quad$ arguments concerning the ways ITEs or ITE programs should do the work of teaching PSTs "about" and "to" diversity

\section{Illustrated by:}

- examples of and challenges to "good/successful pedagogies" for teaching about diversity

- benefits of specialist or purpose-built courses

- a focus on partnerships between ITE providers or other

- papers focused on partnerships with other groups/organizations (including but not limited to schools)

- Failures in teacher education

Code 4:

Barriers/problems relating to PSTs

\section{Characterized by:}

- analysis of challenges relating to PSTs that TEs may confront

\section{Illustrated by:}

- analysis of PSTs' existing beliefs and prior experiences and reports on attempts to change beliefs

\footnotetext{
Code 5:

Characterized by:

Barriers/problems

relating to

- reference to challenges relating to teacher educators'

Teacher educators

\section{Illustrated by:}

- reference to the (challenging) context of an ITE program

- analysis relating to the beliefs or background of TEs themselves

- analysis relating to the skills, knowledge, actions of teacher educators

Code 6:

For diversity

Characterized by:

- advocacy for education as pursuit of social justice and transformation

\section{Illustrated by:}

- substantial engagement with anti-essentialist theories of justice, difference, or identity

- "specialist" literature relating to various references (e.g., feminism, post-colonialism)

- literature that defines or unpacks social justice
} 
Table 4

Summary of Research Questions 2 and 3 and Themes

Research question $\quad$ No. of papers

RQ 2: What claims are made about how teacher education can prepare future teachers for diverse learners, specifically in regard to advice concerning the aims and content of teacher education courses/programs?

Theme 1: The need to provide preservice teachers with a knowledge base about diversity

Theme 2: Principles, pedagogies and practices catering to diverse learners

Theme 3: Affordances of teacher education in regard to teaching for

diversity

RQ 3: What factors are identified as constraining for TEs seeking to prepare future teachers to work with diverse learners?

Theme 1: Contextual constraints (discussed in detail)

Theme 2: Challenges linked to pre-service teachers

Theme 3: Challenges to learning linked to teacher educators 


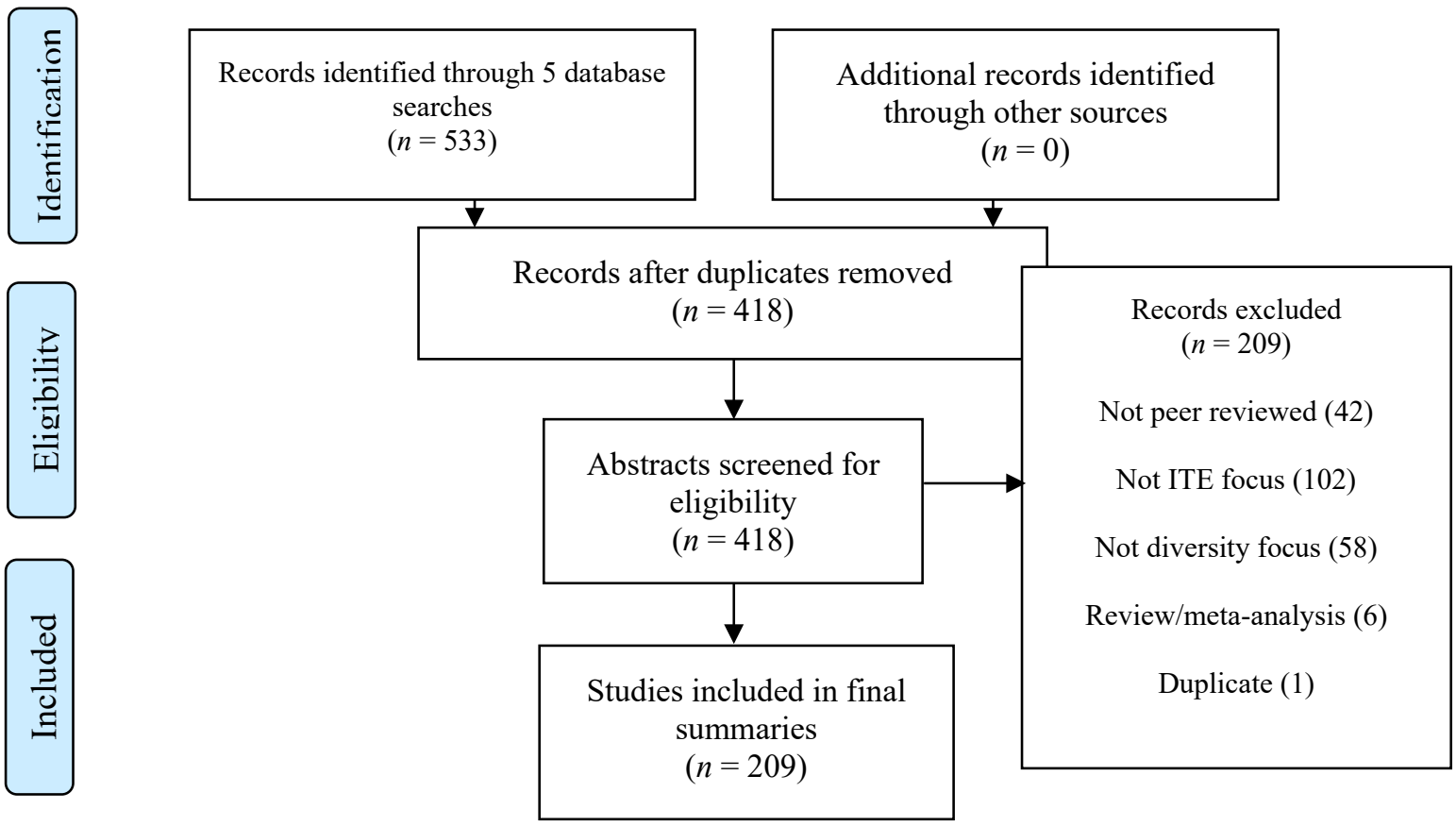

Figure 1. PRISMA flow diagram detailing identification, screening, and inclusion of articles. Adapted from D. Moher et al. (The PRISMA Group; 2009). 


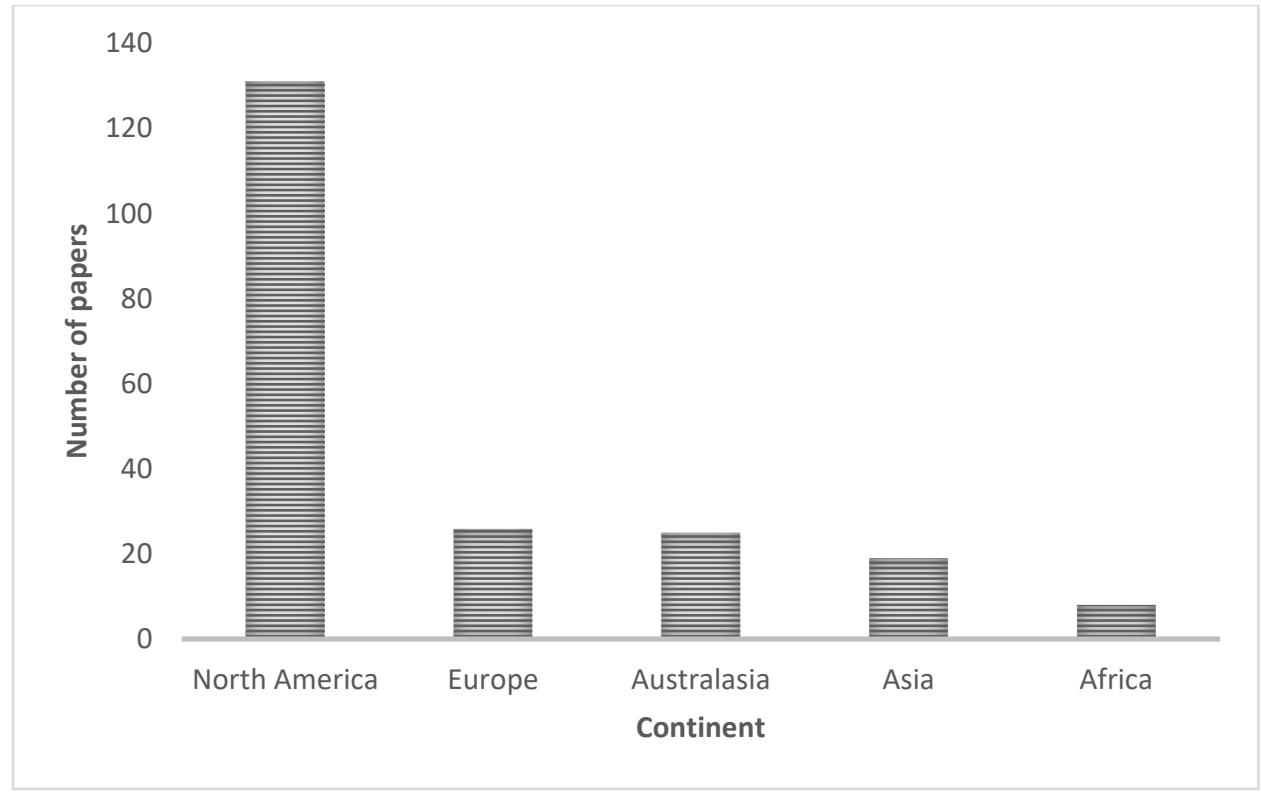

Figure 2. Location of research by continent. 


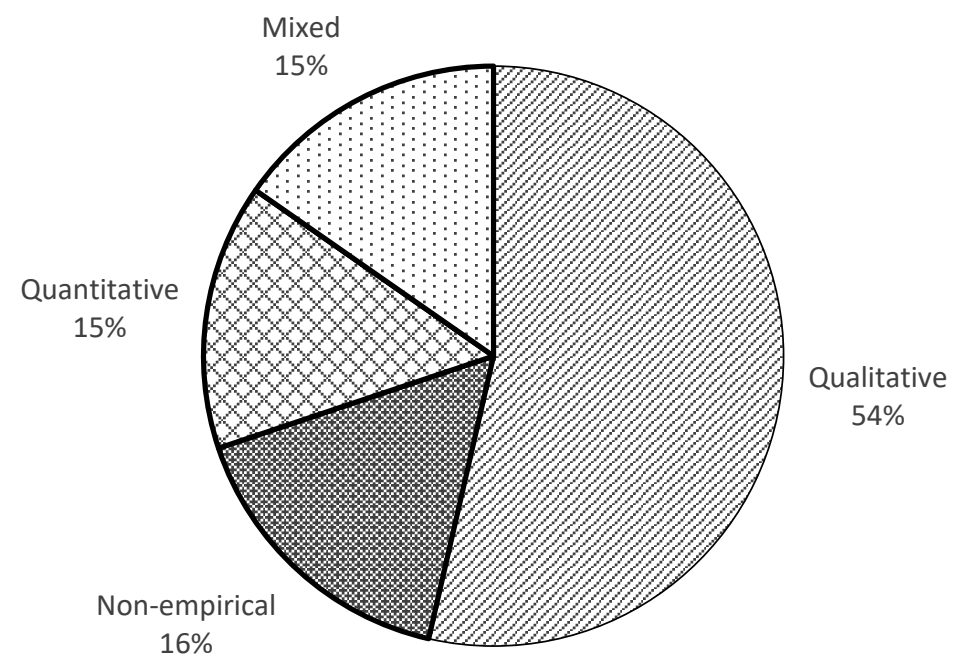

Figure 3. Research design of reviewed literature. 